\title{
Leveraging active-source seismic data in mining tailings: Refraction and MASW analysis, elastic parameters, and hydrogeological conditions
}

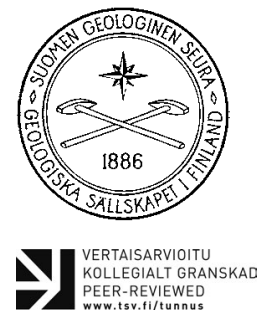

\author{
Raul Mollehuara-Canales ${ }^{\mathrm{I}}$, Nikita Afonin ${ }^{\mathrm{I}}$, \\ Elena Kozlovskaya ${ }^{\mathrm{I}}$, Juha Lunkka ${ }^{\mathrm{I}}$ and Daniele Pedretti ${ }^{2}$ \\ ${ }^{1}$ Oulu Mining School, P.O. Box 3000, 90014 University of Oulu, Finland \\ 2Dipartimento di Scienze della Terra “A. Desio”, Università degli Studi di Milano 20133 \\ Milan, Italy
}

\begin{abstract}
We applied active-source seismic method for the interpretation of elastic parameters in tailings facilities which is essential for evaluating stability and seismic response. The methodology uses different analysis methods on the same dataset, i.e., conventional seismic refraction (SR) to determine compressional-wave velocity $\left(V_{p}\right)$ and multichannel analysis of surface wave (MASW) to estimate shear-wave velocity $\left(V_{s}\right)$. Seismic velocities in conjunction with tailings physics approach revealed interpretable data in terms of elastic parameters and hydrogeological conditions.

The results determined the empirical linear relationships between $V_{p}$ and $V_{s}$ that are particular to an unconsolidated media such as tailings and showed that variability of hydrogeological conditions influences the elastic seismic response $\left(V_{p}\right.$ and $\left.V_{s}\right)$ and the elastic parameters. The analysis of the elastic parameters identified the state condition of the tailings at the time of the survey. The Bulk modulus $K$ that relates the change in hydrostatic stress to the volumetric strain was predominant between 1.0-2.0 GPa. The Young's modulus $E$ in the tailings media was in the low range of $0.15-0.23 \mathrm{GPa}$. Poisson's ratio values in all sections were in the upper limit in the range of $0.37-0.49$, meaning that the tailings media is highly susceptible to transverse deformation under axial compression.
\end{abstract}

Keywords: Seismic refraction, MASW, velocity models, elastic moduli, tailings physics, tailings facilities, monitoring

*Corresponding author (e-mail:raul.MollehuaraCanales@oulu.fi)

Editorial handling: Suvi Heinonen (e-mail: suvi.heinonen@gtk.fi) 


\section{Introduction}

In-situ determination of geotechnical and hydrogeological conditions in tailings is an important expectation in the mining industry. In-situ data aims to get ready and reliable information about the condition and stability of tailings structures (e.g., in a physical, chemical, hydrological, and biological sense). Traditionally, the focus of investigations has been the tailings dam and its state and structural conditions affected by the stress-strain relationship. In contrast, the tailings impoundment, and the hydrogeological conditions of the tailings themselves have received little attention.

Seismic refraction (SR) is the in-situ noninvasive seismic method most used in tailings facilities (e.g. Lghoul et al. 2012). The SR method has played a key role to detect structural boundaries in tailings, yet its application has been limited to the interpretation of the geometry and mapping of the stratigraphy and lithology of the subsurface in tailings domains. SR has been used in this capacity to complement other geophysical techniques such as electric resistivity imaging, radiometric, magnetic, and electromagnetic surveys. With advances in geophysical imaging, seismic methods can provide better depth resolution and can extend their applicability to interpret subsurface conditions. Other seismic methods less frequently investigated in tailings areas include the analysis of seismic surface waves by passive seismic interferometry (Olivier et al. 2017) and MASW (Cracknell et al. 2019). From these applications, it is inferred that, compressional- and shear-wave velocities estimated by seismic methods can be used to determine the elastic parameters of tailings which are important determinations to evaluate settlement and geotechnical conditions in tailings (Davis \& Poulos 1968; Yilmaz \& Miller 2015)

Seismic data analysis is used for characterizing reservoirs and monitoring subsurface pore fluids in several industries such as hydrocarbon exploration and near-surface geophysics. Methods to investigate subsurface conditions and elastic parameters in tailings include laboratory tests (e.g., triaxial tests UU-CU-CD) and in-situ field investigations (e.g., open excavation, boring methods, subsurface sounding). Subsurface sounding methods can include the standard penetration test (SPT) (Yusof \& Zabidi 2018) or more sophisticated cone penetration test (CPT) such as seismic cone penetration test (SCPT), dynamic cone penetration test (DCPT), seismic cone penetration test with pore water pressure measurement (SCPTU) (Robertson \& Cabal 2014; Tschuschke et al. 2020). SCPTU uses the conventional CPT for depth profiling but also includes the seismic piezocone for measuring seismic velocities and the probes for dissipation tests of pore water pressure excess. These methods provide discrete or near-continuous data, but they always require intrusive access to the areas in evaluation, which in most cases is only limited to the perimeter of the facility around and near the embankment or the dike. SCPT has been the method of choice for determining shear wave velocity and correlations with geotechnical conditions in tailings (Zhang \& Lin 1982; Jamiolkowski \& Masella 2015; Sousa \& Gomes 2020), and the application of seismic refraction and MASW in tailings to investigate elastic seismic velocities and their correlation with geotechnical conditions is yet to be developed.

We present in this paper the analysis of SR dataset from a tailings facility in Pyhäsalmi mine, Finland. We introduce the application of seismic refraction and MASW methods to estimate the elastic and hydrogeological conditions of the tailings facility. The approach leverages knowledge from applications in other fields where seismic refraction and MASW methods have been investigated together to evaluate the subsurface structure and conditions of the shallow subsurface (Pegah \& Liu 2016; Olafsdottir et al. 2018; Anukwu et al. 2020; Sarkar et al. 2021). The authors did not find previous research where in-situ non-invasive seismic refraction and MASW have been applied in tailings facilities to explain elastic parameters and hydrogeological conditions. We applied a two-step process to address the technological need for the non-invasive characterisation of tailings facilities. 
First, conventional seismic refraction is applied in the tailings domain to obtain the dataset for the interpretation of body and surface waves in terms of compressional-wave velocity $\left(V_{p}\right)$ and shearwave velocity $(V)$. Second, $V_{p}$ and $V_{s}$ are used to derive the state condition (i.e., a physical condition and changes with respect to its main attributes) of the tailings in terms of elastic parameters (elastic moduli) and the hydrogeological conditions (i.e., porosity, water content, water saturation).

\subsection{Seismic refraction (SR) and MASW analysis in tailings}

Seismic refraction in most near-surface applications have targeted depths of refractors that are less than $100 \mathrm{~m}$ (ASTM 2011). SR has been used in a few studies in tailings domains mainly to delineate layer-horizons and to indicate bed morphology and compaction differences between tailings and basement bedrock (Vanhala et al. 2004; Lghoul et al. 2012; Mollehuara Canales et al. 2021). The method estimates the first arrival times of $\mathrm{P}$-waves to detect changes in the $\mathrm{P}$-wave velocity and produce a layered or a tomographic subsurface model. On the other hand, S-wave velocities mainly applied for mapping earthquake hazard (Tokimatsu \& Uchida 1990) have also found applications in geotechnical investigations. With advances in data acquisition and processing, $S$-wave velocity models can be reconstructed from surface waves (Xia et al. 2009) using methods such as seismic analysis of surface waves (SASW) and multichannel analysis of surface waves (MASW). These methods measure the variation of $S$-waves in soil which can be transformed to stiffness in the depth domain (Park et al. 1999a) and subsequently to geotechnical parameters such as shear and Young's moduli (Soupios \& Kokinou 2016). Therefore, P- and $S$-wave velocities derived from seismic surveys can be used to determine other properties such as shear strength and elastic properties in unsaturated soils (Salem 2000; Rucker 2006; Pegah \& Liu 2016).

The deployment of geophones and data acquisition is similar in both techniques (SR and
MASW) only different at the natural frequencies of geophones. MASW requires a low natural frequency geophone, whereas seismic refraction uses highfrequency ones (Anukwu et al. 2020), but highfrequency geophones (e.g., up to $40 \mathrm{~Hz}$ ) may be acceptable for relatively shallow depth applications (e.g., <10 m) (Lu 2017). As conventional seismic refraction uses mostly 4.5 and $10 \mathrm{~Hz}$ frequency geophones the data acquired by the method can be used to retrieve and estimate surface wave information and $\mathrm{S}$-wave velocity profiles in the shallow subsurface. For most common soil sites, the offset range of 10-100 $\mathrm{m}$ is optimal for recording surface waves in the frequency range of $5-50 \mathrm{~Hz}$, and in the phase velocity range of $50-1000 \mathrm{~ms}^{-1}$ (Park et al. 1999b). Generally, the seismic wave velocities in tailings are in the range of 500-1600 $\mathrm{ms}^{-1}$ for P-wave and 200-500 $\mathrm{ms}^{-1}$ for S-wave, but these values are case dependent and may vary for specific cases. This study used $4.5 \mathrm{~Hz}$ geophones to source the same dataset for both $\mathrm{P}$ - and $\mathrm{S}$-wave analysis.

\section{Research methodology}

\subsection{Site and experimental setup}

The study area is the tailings facility known as pond A at Pyhäsalmi mine site located in the south of Northern Ostrobothnia region, Finland (Fig. 1). The tailings facility has undergone rehabilitation from 1999 to 2002 and at present it has a cover system on the surface except in the centre where a water pond is maintained. The area is about 41 hectares and excluding the cover layers contains about $10 \mathrm{Mt}$ of tailings (Outokumpu Mining Oy 1999; Pyhäsalmi Mine Oy 2007).

The study consisted of two steps as presented in Fig. 2. In stage I, conventional seismic refraction data is used to obtain velocity models for P-wave $\left(V_{p}\right)$ and $\mathrm{S}$-wave $(V)$ at several locations of the tailings facilities identified as survey lines in Fig. 1. For this, compressional-wave velocity $(V)$ is determined from the travel times of P-wave first 


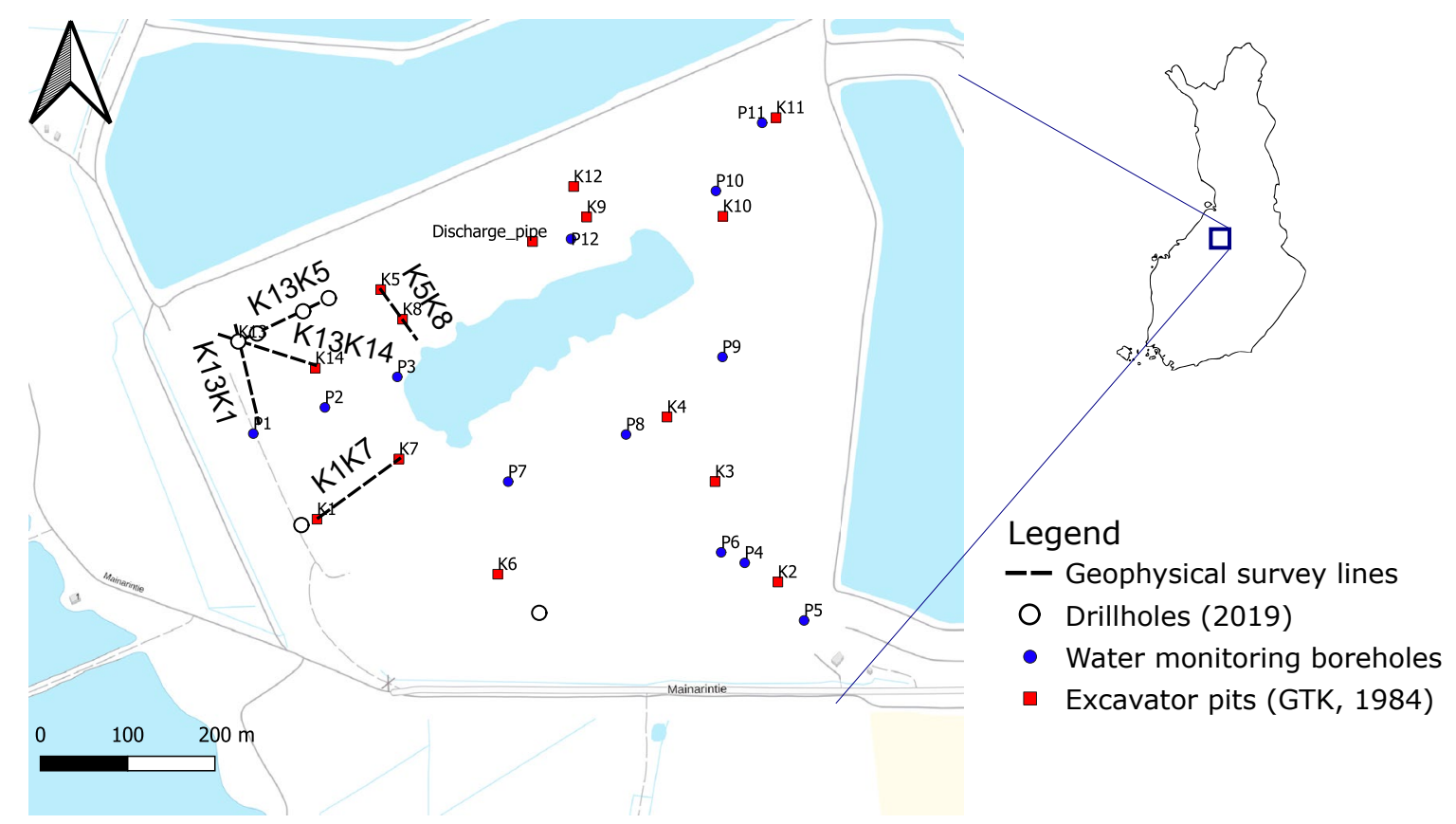

Figure 1. Site location and geophysical seismic refraction survey lines (ETRS89/TM35FIN 63.663oN, 26.013oE) (Base maps derived from QGIS/OSM).

arrivals, and shear-wave velocity $(V)$ is determined from the dispersion curves of the surface waves (Rayleigh) evaluated using MASW technique. The layered $V_{p}$ models are computed from the travel time curves. The $V_{p}$ distribution from the layered together with the knowledge of the site (i.e., stratigraphy and bulk mass density) model serve also as constraints for the parameterization of the initial model in the inversion and estimation of $V_{s}$ models.

In stage II, the elastic properties of the tailings are computed concerning analogous 'rock physics' principles for both compressional and shear velocities. First, the subsurface condition in terms of stratigraphy, bulk mass density, and water saturation is measured from core samples at discrete locations of the tailings area and used for determining the empirical relationships between the elastic velocities and the hydrogeological conditions. The subsurface conditions below the phreatic level were assumed to be at saturated conditions. The seismic response is then cross evaluated in terms of the elastic parameters and their relationship with the hydrogeological conditions at the subsurface of the tailings.

The tailings physics approach assumes that the tailings are subject to small changes of stress and hence linearity for the elastic parameters (Schön 2015). The theory of linear elasticity (Landau \& Lifshitz 1970) for a homogeneous isotropic media describes the elastic wave propagation and the interdependence of the elastic moduli by the equation 1 :

$$
2 \mu(1+v)=E=3 K(1-2 v) \quad(\text { Eq. } 1)
$$

The two independent elastic body waves are correspondent to the elastic moduli via the compressional P-wave velocity $\left(V_{\mathrm{p}}\right)$ and the shear, transversal, S-wave velocity $\left(V_{\mathrm{s}}\right)$ : 


\section{Seismic refraction (I)}

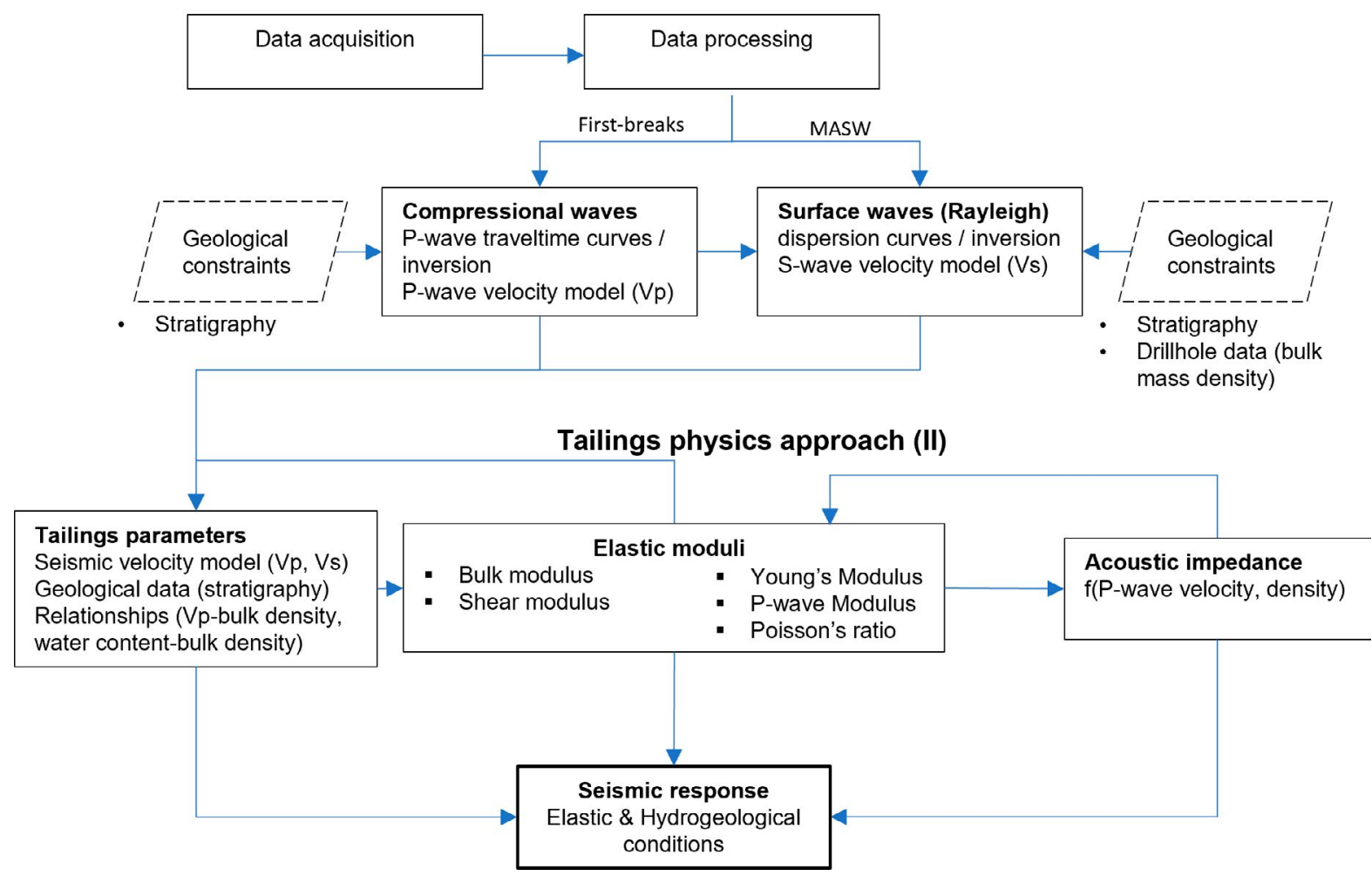

Figure 2. Seismic refraction and Tailings physics approach for interpretation of elastic and hydrogeological conditions in tailings.

$$
\begin{aligned}
& V_{p}=\sqrt{\frac{M}{D_{\text {bulk }}}}=\sqrt{\frac{E}{D_{\text {bulk }}} \cdot \frac{1-v}{(1+v) \cdot(1-2 v)}}=\sqrt{\frac{\lambda+2 \mu}{D_{\text {bulk }}}}=\sqrt{\frac{k+\left(\frac{4}{3}\right) \cdot \mu}{D_{\text {bulk }}}} \\
& V_{s}=\sqrt{\frac{\mu}{D_{\text {bulk }}}}=\sqrt{\frac{E}{D_{\text {bulk }}} \cdot \frac{1}{2 \cdot(1+v)}}
\end{aligned}
$$

The ratio of the two wave velocities is controlled by the Poisson's ratio given by (Schön 2015):

$$
v=\frac{0.5\left(V_{p}^{2}-2 V_{s}^{2}\right)}{V_{p}^{2}-V_{s}^{2}}
$$

The impedances $I_{p}$ and $I_{s}$, is given by:

$$
I_{p}=D_{\text {bulk }} * V_{p} \quad ; I_{s}=D_{b u l k} * V_{s},
$$

where the bulk mass density is given by $D_{\text {bulk }}=\frac{\gamma}{g}$ so that dimensionally the SI unit for all elastic moduli is expressed in $\mathrm{GPa}$ (except Poisson ratio, (U) that is unitless): 
$K-$ Bulk modulus $[G P a]$

$\mu$ - Shear modulus [GPa],

$E$ - Young's modulus [GPa],

$M$ - P-wave modulus [GPa],

$\gamma$ - bulk unit weight $\left[\mathrm{N} / \mathrm{m}^{3}\right]$

$g-$ gravitational acceleration $\left[\mathrm{m} / \mathrm{s}^{2}\right]=9.80665$

$I_{p, s}-$ specific acoustic impedance $[\mathrm{Pa} . \mathrm{s} / \mathrm{m}]$, or $[\mathrm{kg} / \mathrm{m} 3 \mathrm{x} \mathrm{m} / \mathrm{s}]$

A description of the elastic moduli follows (Schön 2015; Mavko et al. 2020). Bulk modulus (K) describes the resistance of the tailings to compression and it is defined as the ratio of the hydrostatic stress, $\sigma$, to the volumetric strain. Shear modulus $(\mu)$ (or modulus 'rigidity' describes the response to shear, and it is a measure of elastic shear stiffness. Young's modulus $(E)$ describes the response to linear stress and it is defined as the ratio of the stress to the strain in a uniaxial stress state. P-wave Modulus $(M)$ is defined as the ratio of stress to strain in a uniaxial strain state. Poisson's ratio $(v)$ describes the response in the direction orthogonal to uniaxial stress and it is defined as the (negative) ratio of lateral strain to axial strain in a uniaxial stress state. Lame's constant $(\lambda)$, is the first lame's parameter related to the bulk modulus and serves to simplify the stiffness matrix in Hooke's law.

\section{Results and interpretation}

\subsection{P-wave velocity model}

The theory of seismic survey is not covered in detail here but this is widely documented elsewhere (Redpath 1973; Idziak \& Dubiel 2011; Pegah \& Liu 2016). Data was acquired using a conventional set of 24 geophones $(4.5 \mathrm{~Hz})$ placed every $5 \mathrm{~m}$ for a given array (K1K7, K13K14, K13K5, K13K1) except for $\mathrm{K} 5 \mathrm{~K} 8$ where the spacing was $3 \mathrm{~m}$. The seismic energy consisted of hammer strikes on a steel plate through seven-shot points that were distributed at $-25,2.5,27.5,57.5,87.5,112.5$, and $140 \mathrm{~m}$ distance from the starting point of the survey line. The acquisition parameters included a sampling period of $1 \mathrm{~ms}$ and a recording length of $0.3 \mathrm{~s}$. Processing and modelling of the seismic data for P-wave velocity used Geometrics' software package SeisImager/2D, Pickwin, and Plotrefa (Geometrics Inc. 2005).

The P-wave first breaks method is applied in all shot records for each trace in Pickwin. Plotrefa module is used to transform the first arrival picks into travel time curves and subsequent inversion of the data calculated the P-wave velocity $\left(V_{p}\right)$ models (Fig. 3). The process set up the initial velocity model with the field constraints (i.e., stratigraphy) and the minimum and maximum velocities derived from the travel time curves. The solution for a semiconstrained problem used an iterative, least-squares approach and created a velocity model for each travel time (Mollehuara Canales et al. 2021).

\subsection{Surface waves dispersion curves and velocities}

In MASW method, the dispersion property of surface waves is analysed to determine shear-wave velocity $(V)$ models. The procedure consisted of three steps, acquisitio $v \mathrm{n}$ of dispersive ground roll data, construction of the dispersion curves, and inversion of dispersion curves to $S$-wave velocity $(V)$ cross-sections. The dispersion curves were calculated from the same seismic refraction dataset using the Geopsy software (Geopsy 2021) and for this analysis, the source positions at the beginning of the profiles were considered. We applied acquisition geometry that allows us to produce surface waves, which could be processed by the MASW technique. In addition, a two-dimensional Fourier transform generated a conventional frequency wavenumber (F-K spectrum) that included processing parameters for the frequency range $4-40 \mathrm{~Hz}$ with a band width of $0.2 \mathrm{~Hz}$. No additional procedure was necessary for surface wave energy enhancement. Results of the spectral analysis and corresponding dispersion curves are presented in Fig. 4. 
a)

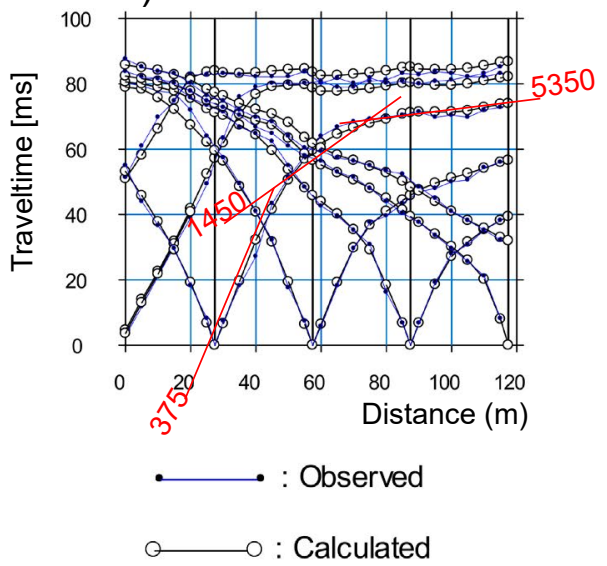

K1K7

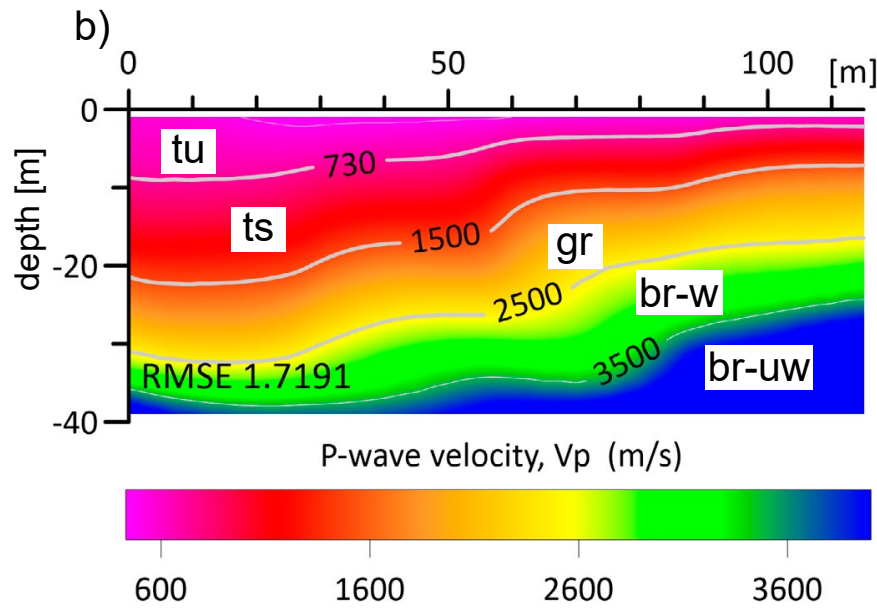

Figure 3. Example of P-wave velocity modelling for line K1K7. Observed and calculated travel times (left) and P-wave velocity layered model after inversion (right). Vp contour levels (in white/grey lines) were matched to stratigraphic units in the tailings to depict: tu - unsaturated tailings, ts - saturated tailings, gr - underlying ground, br-w - bedrock weathered, br-uw - bedrock un-weathered. The source for the delineation of the stratigraphic units is a geological model from a previous study by Mollehuara-Canales et al. (2021).
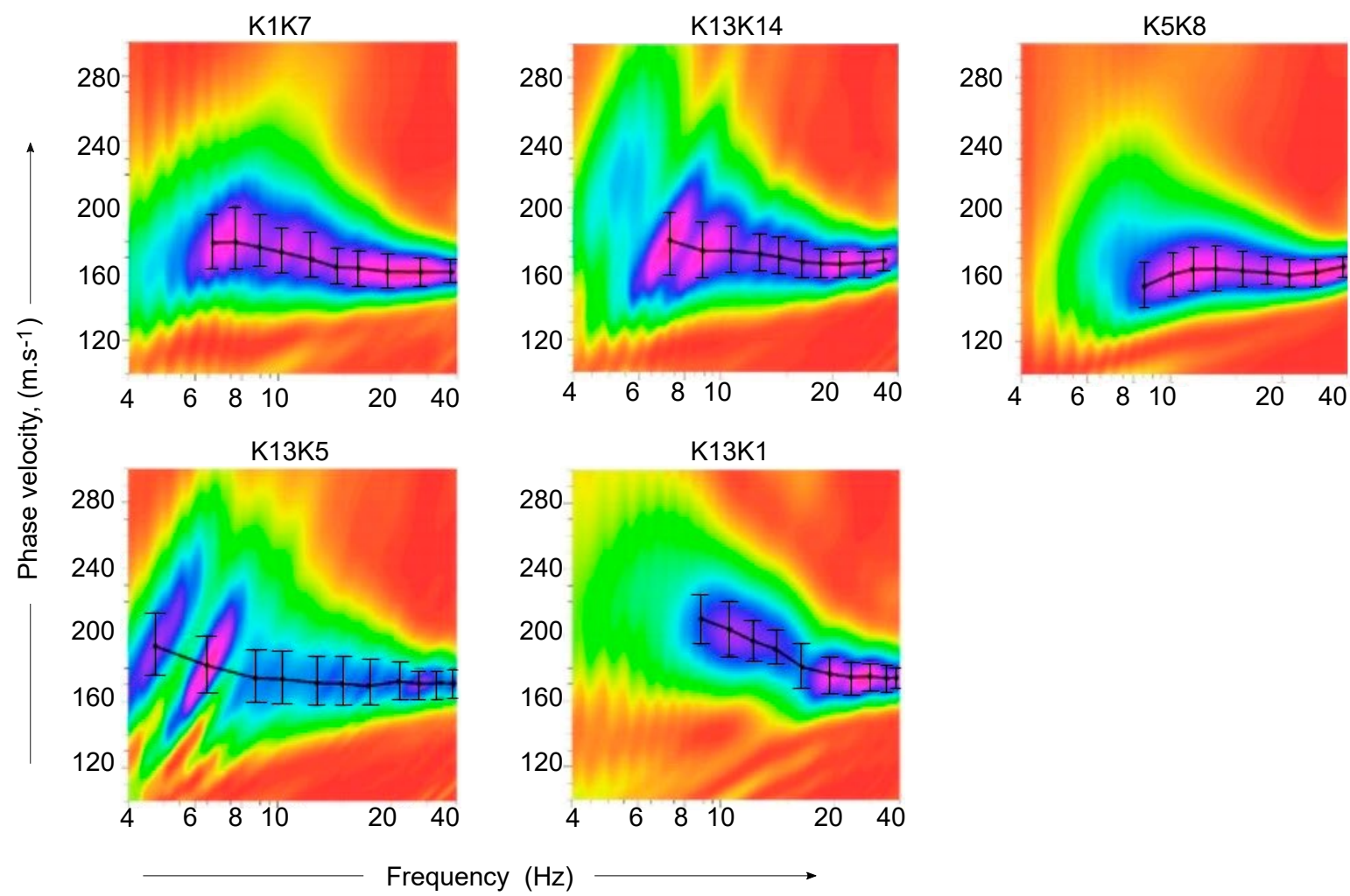

Figure 4. Spectral analysis for dispersion curves, obtained by the MASW method. Error bars are indicated. 
The dispersion curves consist of only the fundamental mode characterized by normal dispersion in most cases. In most cases, the phase velocities of Rayleigh waves are characterized by normal dispersion and are distributed within the tailings. As the properties of tailings have small variations with depth as observed from the drilling data, it is assumed that phase velocities of different modes be close to the velocity of the fundamental mode and within the error bar. Phase velocities are in the range of $150-200 \mathrm{~m} / \mathrm{s}$ which is typical for sandy media. Therefore, the signals are considered as being distributed only inside the tailings media and not in the consolidated ground or bedrock. The latter is usually characterized by higher velocities. As there is no unique way of defining model parameterization, it was critical for the initial model to consider known geological constraints such as number of layers and bulk mass density from the stratigraphic units and estimated parameters such as $V_{p}$ from the $\mathrm{SR}$ model. The parameterization of the initial model for solving the inversion problem and for determining $S$-wave velocity profiles are presented in Table 1.

Table 1. Initial parameters for model inversion.

\begin{tabular}{|c|c|c|c|c|c|c|c|c|}
\hline Layer & Stratum & $\begin{array}{c}\text { Depth } \\
\text { (m) }\end{array}$ & $\begin{array}{c}\mathbf{v}_{p} \text { from } \\
\text { seismic } \\
\text { refraction } \\
\operatorname{model}(\mathrm{m} / \mathrm{s})\end{array}$ & $\begin{array}{l}\mathrm{v}_{p} \text { for } \\
\text { initial } \\
\text { model } \\
(\mathrm{m} / \mathrm{s}) \\
\end{array}$ & $\begin{array}{c}\text { bulk } \\
\text { mass } \\
\text { density } \\
\left(\mathrm{kg} / \mathrm{m}^{3}\right)\end{array}$ & Depth (m) & $\begin{array}{l}\text { Poisson's } \\
\text { ratio }\end{array}$ & $\begin{array}{c}\mathbf{V}_{s} \text { _wide } \\
\text { range } \\
(\mathrm{m} / \mathrm{s})\end{array}$ \\
\hline 1 & cover & 1 & [300-500] & 400 & 1450 & {$[0-2]$} & $0.2-0.3$ & [100-1200] \\
\hline 2 & $\begin{array}{l}\text { tailings } \\
\text { unsaturated }\end{array}$ & 5 & [300-500] & 480 & 1960 & [1-5] & $0.2-0.3$ & [100-1200] \\
\hline 3 & $\begin{array}{l}\text { tailings } \\
\text { unsaturated }\end{array}$ & 10 & [400-900] & 750 & 2000 & [3-10] & $0.2-0.3$ & [100-1200] \\
\hline 4 & tailings saturated & 15 & [750-1500] & 1100 & 2100 & [8-15] & $0.2-0.3$ & [100-1200] \\
\hline 5 & tailings saturated & 20 & [750-1500] & 1500 & 2100 & [13-20] & $0.2-0.3$ & [100-1200] \\
\hline 6 & $\begin{array}{l}\text { underlying } \\
\text { ground }\end{array}$ & 30 & [1000-5750] & $1500-5750$ & [2250-2635] & {$[>20]$} & $0.2-0.3$ & [500-3500] \\
\hline
\end{tabular}

The inversion procedure used the Dinver module included in Geopsy software to model the theoretical and the experimental dispersion curves in terms of phase velocity and frequency (Fig. 5). The Dinver module is based on the global optimization neighbourhood algorithm (Sambridge 1999a, $1999 \mathrm{~b})$. In the inversion process, 500 starting models were generated randomly by Monte-Carlo simulation and 10000 models were generated with the neighbourhood algorithm. The inversion resulted in a $1 \mathrm{D} S$-wave velocity model with a minimal misfit of less than 0.007 (or $0.7 \%$ ) (Fig. 6).

\subsection{S-waves and seismic velocity structure}

Fig. 6 presents the seismic velocity and stratigraphic structure for all the SR profiles investigated in the tailings area. $V_{p}$ was represented by averaged values from the correspondent $V_{p}$ model derived by SR (section 3.1). In all profiles, $V$ increased marginally with depth to about $175 \mathrm{~m} / \mathrm{s}$ in the region mapping the tailings media, whereas the region near the embankment (K13K1) showed a slightly higher $V_{s}$ up to $210 \mathrm{~m} / \mathrm{s}$.

The resulting 1D $S$-wave velocity models presented in Fig. 6 consisted of six layers and the profiles in all of them are near the same. Average velocity profiles are presented in Table 2. 

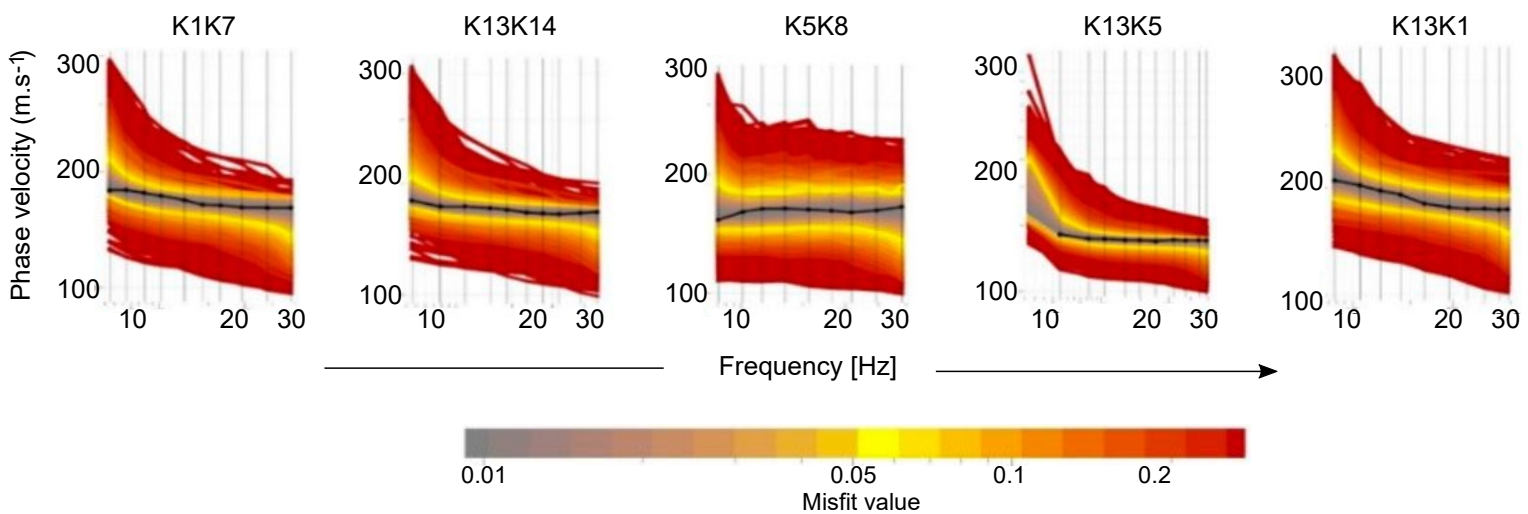

Figure 5. Theoretical (coloured from red to grey) and experimental (black) dispersion curves for each of the survey lines in the tailings area.

Figure 6.

Stratigraphic and seismic velocity (Vp and Vs) structure in the tailings facility of Pyhäsalmi mine, Finland. The stratigraphy and $\mathrm{Vp}$ structure serve as parameterization of the initial model to obtain the Vs structure in the MASW inversion. The stratigraphy structure was derived from a prior geological knowledge (Mollehuara Canales et al. 2021). P-wave velocity structure depicts average $V p$ values from the seismic refraction model.

Average stratigraphic and seismic velocity ( $V p$ and $V s)$ structure

$\mathrm{K} 1 \mathrm{~K} 7$
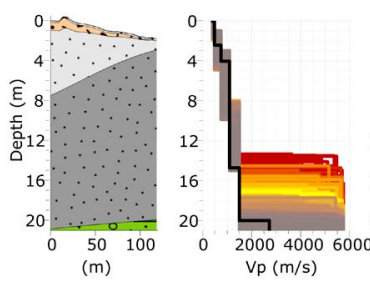

K13K14
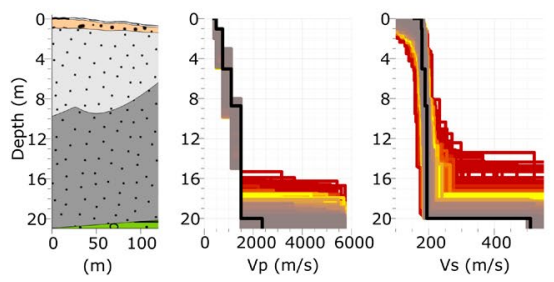

Legend for stratigraphic structure

$\therefore \therefore$ protective compacted diamic/till layer, 0.3-1.2m

$\because$ zone of unsaturated tailings

$\therefore \because$ zone of saturated tailings

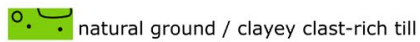

minimum misfit for seismic velocities

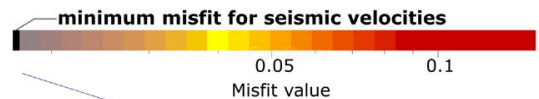

$\mathrm{K} 5 \mathrm{~K} 8$
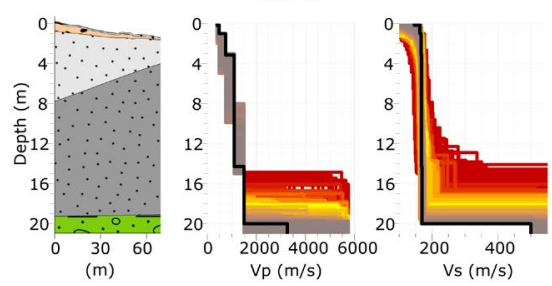

K13K5
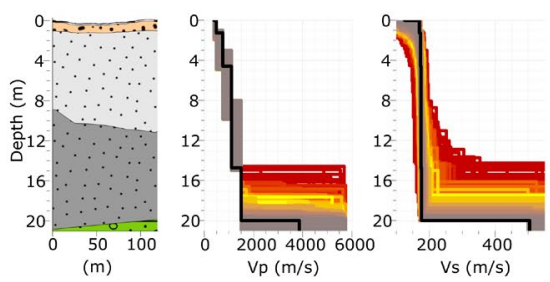

K13K1
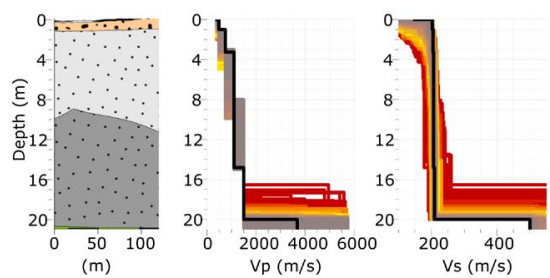
Table 2. 1D average shear-wave velocity, $V_{s}(\mathrm{~m} / \mathrm{s})$ estimated by inversion of Rayleigh wave dispersion curves (tu - unsaturated tailings, ts - saturated tailings, $g r$ - underlying ground).

\begin{tabular}{|c|c|c|c|c|c|c|c|}
\hline Layer & Stratum & Depth (m) & K1K7 & K13K5 & K5K8 & K13K14 & K13K1 \\
\hline 1 & cover & 1 & 160 & 171 & 162 & 161 & 205 \\
\hline 2 & tu & 5 & 175 & 173 & 166 & 167 & 206 \\
\hline 3 & tu & 10 & 176 & 175 & 167.5 & 167.5 & 209 \\
\hline 4 & ts & 15 & 176 & 175 & 168 & 168 & 209 \\
\hline 5 & ts & 20 & 176 & 176 & 170 & 170 & 211 \\
\hline 6 & gr & 30 & $>210$ & $>210$ & $>210$ & $>210$ & $>210$ \\
\hline
\end{tabular}

\subsection{Tailings empirical relations}

Dataset corresponding to tailings core samples along the survey line K13K5 was evaluated at various depths $(z)$ for bulk-wet mass density, $\left(D_{\text {bulk-wel }}\right)$. gravimetric water content $\left(\theta_{g}\right)$ and corresponding P-wave velocity $\left(V_{p}\right)$. The procedures for determining bulk-wet mass density and gravimetric water content are documented in Mollehuara-Canales et al. (2020). P-wave velocity values are the corresponding measurements from the seismic refraction method. First, in Fig. 7a we show a linear regression fit function that

$$
D_{\text {bulk-wet }}=2.076-0.0002507 * V_{p}-0.01745 * Z
$$

A second plot is illustrated in Fig. 7b which shows a relationship between the bulk mass density $\left(D_{\text {bulk }}\right)$ and the gravimetric water content $\left(\theta_{g}\right)$. The

$$
D_{\text {bulk-wet }}=0.6624 * \theta_{g}+1.8713
$$

In Fig. 8, 1D velocity models from SR (average $V$ ) and MASW analysis $(V)$ are also evaluated in a simple linear regression model to establish the relationship between $\mathrm{P}$ - and S-wave velocities for each survey line. The plots show the variability of seismic velocities for $V_{p}$ and $V_{s}$ measured at different locations in the tailings media. For instance, for a starting $V_{p}$ of $500 \mathrm{~m} / \mathrm{s}, V_{s}$ varies in a close range of $164-176$ m/s for lines K1K7, K5K8, K13K14, approximates the relationship between $V_{p}$ and bulkwet mass density $\left(D_{\text {bulk-wel }}\right)$. The relationship fits best in the depth domain suggesting the influence of the unconsolidated nature of the tailings media and the different densification stages resulting from the consolidation process. From drill core samples, the average variability of the bulk mass density increases with depth although not significantly (Table 1). Also, it is expected that water saturation varies in the unsaturated zone and increases towards the phreatic line. Both aspects influence the $V_{p}$ values with depth. The corresponding empirical relationship is:

relationship of interest for back calculating $V_{p}$ is the equation corresponding to $\left(D_{\text {bulk-wet }}\right)$ as a function of $\left(\theta_{g}\right)$.

(Eq. 7)

$\mathrm{K} 13 \mathrm{~K} 5$ and is around $202 \mathrm{~m} / \mathrm{s}$ for line $\mathrm{K} 13 \mathrm{~K} 1$. The former lines are mapping the relationship in the tailings media whereas line K13K1 is mapping the subsurface near the embankment material that is assumed to be a mix of till and compacted soil overlying coarse sandy tailings. The rate of change of $V_{s}$ with respect to $V_{p}$ is similar for all survey lines which is shown in the relations of Fig. 8. For line K13K14, a small variation suggests that some other subsurface 
a) Relationship: $V_{p}, D_{\text {bulk-wet }}$ depth

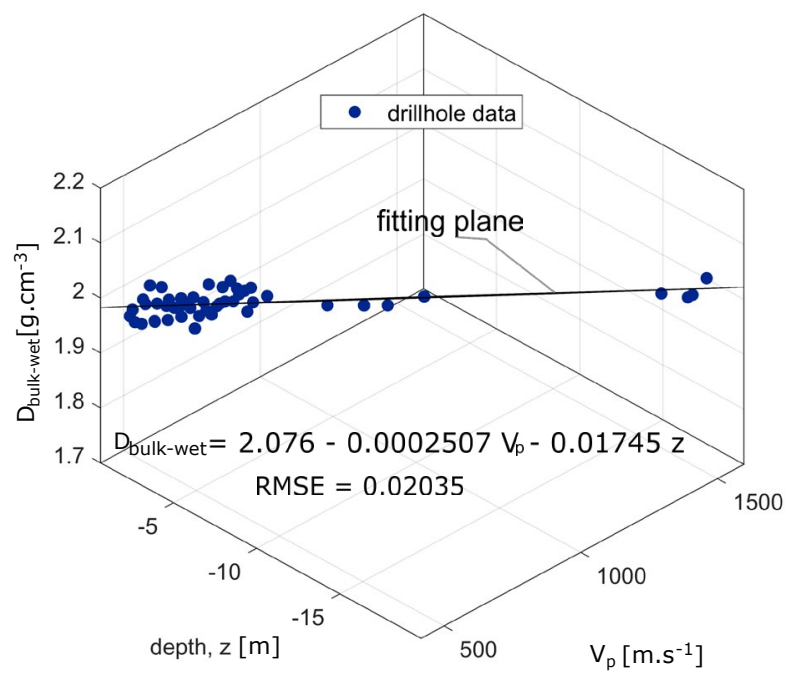

b) Relationship: $\mathrm{D}_{\text {buk, }_{\mathrm{f}}} \theta_{\mathrm{g}}$

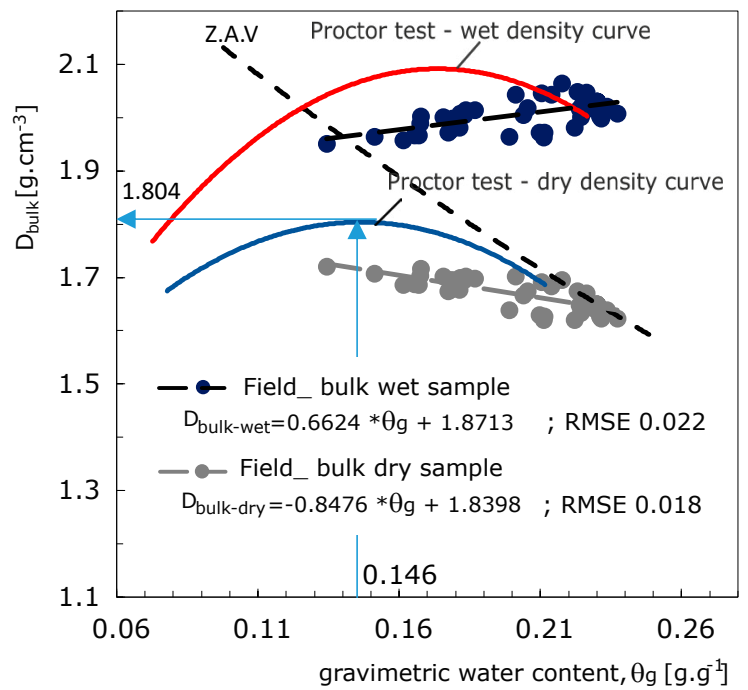

Figure 7. (a) Relationship based on linear regression for P-wave velocity $(\mathrm{Vp})$ and bulk-wet mass density $\left(D_{\text {bulk-wet }}\right)$ in the depth domain (z). Measured data correspond to core samples along the survey line K13K5. (b) Relationship between bulk mass density $\left(D_{\text {bulk }}\right)$ and gravimetric water content $\left(\theta_{g}\right)$. for the same core samples along survey line K13K5. Sample data and fit lines are plotted overlying a typical laboratory compaction test curve for reference.

Figure 8. Linear relationships for Vp and Vs at corresponding survey lines in the tailings area of Pyhäsalmi mine.

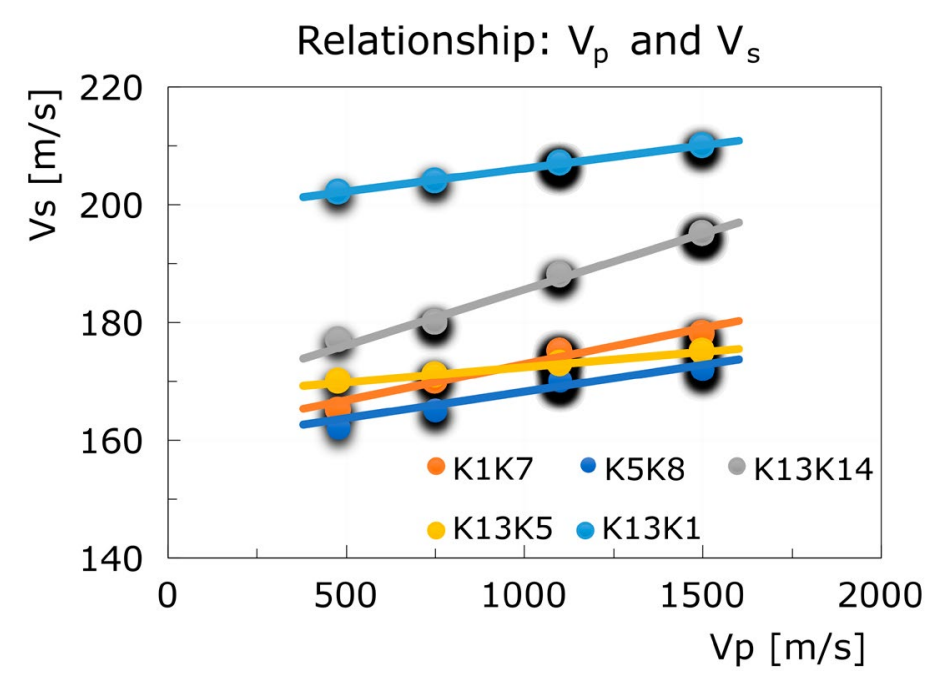

silicate rocks (Castagna et al. 1985), or pure porous lithologies (Greenberg \& Castagna 1992). The relations shown in Fig. 8 apply to an unconsolidated tailings media, which is specific to the Pyhäsalmi tailings and are given by the following equations: 


$$
\begin{aligned}
& V_{s(K 1 K 7)}=0.0123 * V_{p(K 1 K 7)}+160.65 \\
& V_{s(K 5 K 8)}=0.009 * V_{p(K 5 K 8)}+159.28 \\
& V_{s(K 13 K 14)}=0.0189 * V_{p(K 13 K 14)}+166.75 \\
& V_{s(K 13 K 5)}=0.0051 * V_{p(K 13 K 5)}+167.34 \\
& V_{s(K 13 K 1)}=0.0079 * V_{p(K 13 K 1)}+198.26
\end{aligned}
$$

From here, the elastic parameters for the seismic response $\left(V_{p}\right.$ and $V$ ) on each survey line were calculated following equations 2, 3, 4, and 5, and by using the corresponding empirical relationship between $V_{p}$ and $V_{s}$ from equations $8,9,10,11$, and 12.

\subsection{Elastic moduli interpretation}

The elastic moduli properties of the tailings are represented by survey lines in Fig. 9 and by the water saturation conditions in Fig. 10. The range of values for the elastic moduli are within similar ranges for the survey lines at various locations of the tailings facility (Fig. 9). For instance, the range of values is between 0.37-0.49 for Poisson's ratio, 0.06-0.09 GPa for shear modulus, 0.15-0.28 GPa for Young's modulus, and 0.1-4.2 GPa for bulk modulus. Note that $\mathrm{Vp} / \mathrm{Vs}$ ratio also varies from 2.5 to a maximum of 8.5 .

All elastic parameters show a direct proportionality with the seismic velocities $V_{p}$ and $V_{s}$. For Poisson's ratio the relation is a logarithmic function and asymptotic near the maximum value of 0.5 . For shear modulus and Young's modulus, it is a linear relationship, whereas for Bulk modulus the relation is an exponential function. In the Pyhäsalmi tailings, the elastic velocities increase with depth, and it is expected that elastic moduli will increase following the behaviour of these functions. This means that compressive and shear deformation (given by $E$ and $\mu$ respectively) in the tailings increases linearly with depth, but the volumetric deformation defined by $K$ is exponential. The plots also show that Vs has greater influence than $\mathrm{Vp}$ to increase the slope
(Eq. 8)

behaviour of the functions representing the elastic moduli which are mainly explained by the drop of Vs with depth and/or higher saturation.

From all the survey lines, only K13K1 maps a region near the embankment and distinguishes apart from all the other transects mapping the tailings media (light-grey dots in the plots of Fig. 9) by showing higher values for $V$, and elastic parameters. Near the embankment, the tailings media is mixed with other materials of low permeability, and it has been compacted to provide a containment wall for the tailings. Also, as the phreatic line is low, the pore space is less saturated. This confirms that high values of elastic moduli depend on high values of $V$, and this in turn is influenced by the presence of water in the pore space of the tailings.

In Fig. 10, the elastic moduli values have been grouped by the type of tailings media, i.e., unsaturated tailings (tu) and saturated tailings (ts). The plots show the effect of saturation and location (depth). The Poisson's ratio of the tailings media below the water level is high in the upper limit of 0.48-0.49, whereas the unsaturated tailings (at 0.5 to 0.8 saturation) vary from 0.37 up to 0.48 . This agrees with typical Poisson's values between 0.30 0.40 for unsaturated tailings (Psarropoulos \& Tsompanakis 2008; Ormann et al. 2011; Knutsson et al. 2018; Lu \& Chang 2019). Shear modulus seems not affected in these two tailings groups and the minor variability is depicted only when plotted against $V_{s}$ values. It is also noted from the plot against $V_{p} / V_{s}$ ratio that the shear modulus varies in the same range for both unsaturated and saturated tailings and therefore they have the same shear 


\section{Elastic moduli charts by SR line}
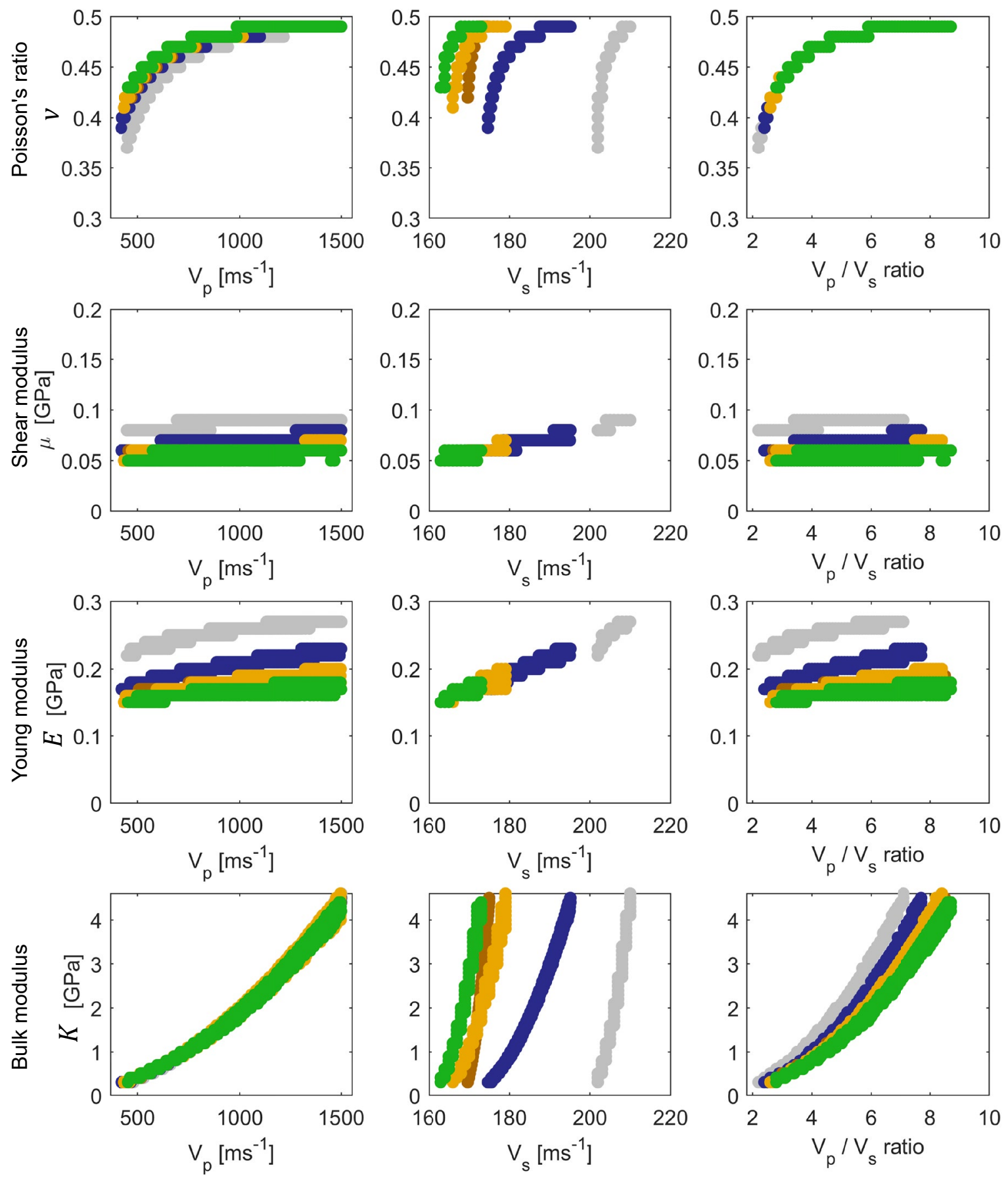

- K13K14

- $\mathrm{K} 5 \mathrm{~K} 8$

- K13K5

K13K1

Figure 9. Elastic moduli calculated from seismic refraction data at various locations of the tailings facility (survey lines K1K7, K13K14, K5K8, K13K5, K13K1). K13K1 corresponds to a line near and along the western embankment; all the other lines are situated within the internal domain of the tailings facility (see Figure 1 ). 


\section{Elastic moduli charts by tailings media}
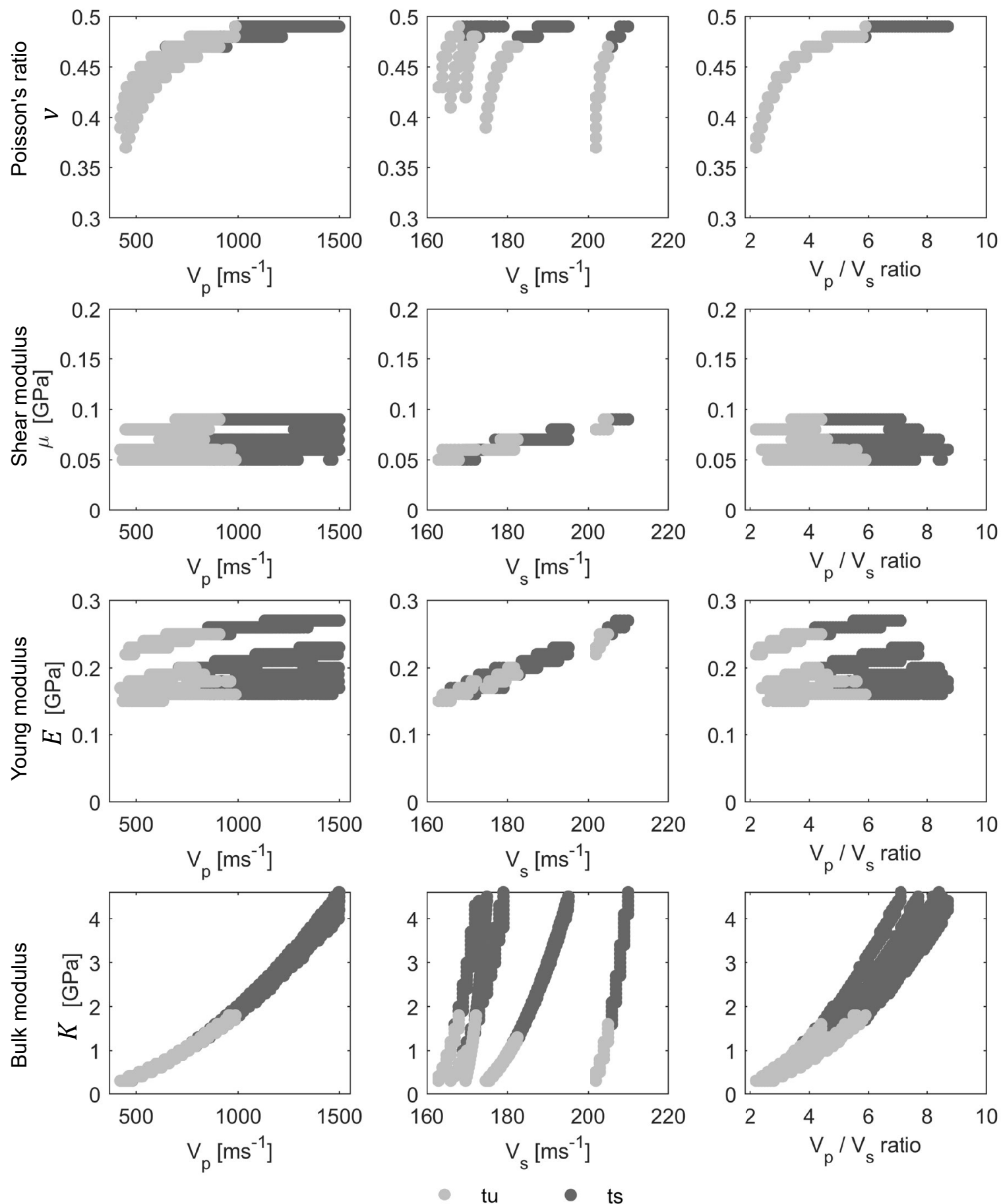

Figure 10. Elastic moduli calculated from seismic velocity models and plotted by tailings stratigraphy: tu - unsaturated tailings, ts - saturated tailings." 
K1K7

a)

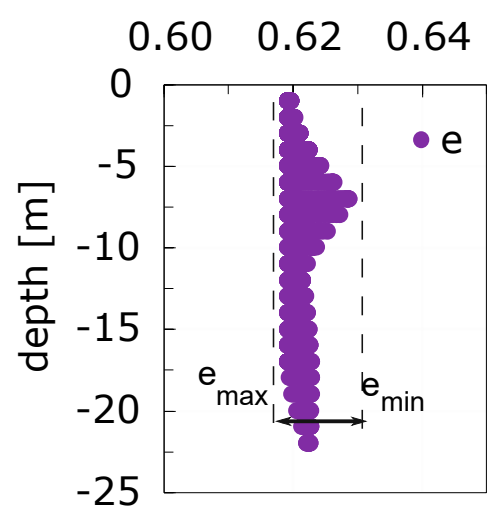

b)

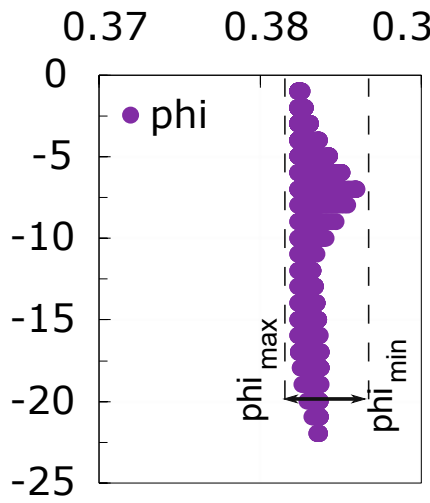

c)

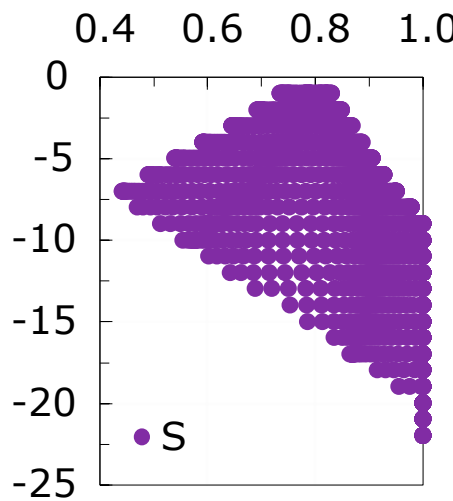

Figure 11. 1D representation of hydrogeological conditions in the profile line $\mathrm{K} 1 \mathrm{~K} 7$ of the tailings derived from SR data: $\mathrm{e}-$ void ratio, phi - porosity, S - water saturation.

behaviour at any location of the tailings. Young's modulus is slightly higher in saturated tailings than unsaturated tailings, but this may be due to higher $V_{p}$ values and increased stiffness at deeper zones in the tailings. Bulk modulus increase as the $V_{p} / V_{s}$ ratio increases toward the saturated zone.

From the tailings elastic parameters and the relationship determined for $V_{p}-D_{\text {bulk-wet }}-\theta_{g}$ (section 3.4) it was possible to estimate hydrogeological state conditions in the tailings at the time of the survey (i.e., porosity, void ratio, water content, and water saturation). For instance, in profile $\mathrm{K} 1 \mathrm{~K} 7$ the porosity, void ratio, and water saturation variation are presented as 1D scatter plots (Fig. 11). Porosity is almost invariable around 0.38 and 0.39 , and the void ratio is in the range of $0.61-0.62$ with similar behaviour in the survey profiles.

In Fig. 12 we show the relationship of the elastic moduli to water saturation $(S)$ in the tailings which is presented as density scatter plots. The graphs describe the average state condition of the tailings at the corresponding survey locations. The tailings media present a wide range of water saturation between 0.5 to 1.0 whereas near the embankments the water saturation shows less variability from 0.8 to 1.0 . The variability of the calculated elastic parameters reveals its dependence on water saturation which is explained by the relationship between the effective stress and the hydraulic pore pressure stress. The density function that better approximates the randomness of the data are estimated using a non-parametric kernel density estimator (ksdensity function in Matlab) that applies to univariate and bivariate data. It was used to infer the characteristics of the dataset in a plot that estimates its probability density function. In this way, the state condition of the tailings media at the time of the survey is depicted by the region with dense data points.

Values for elastic parameters have been approximated and summarised in Table 3 considering the predominant water saturation in the tailings at the time of the survey (Fig. 12). The average values are also compared to other studies and techniques.

At water saturation of $0.8-1.0$, Young's modulus in the tailings was between 0.18 to 0.21 $\mathrm{GPa}$, and for the line $\mathrm{K} 13 \mathrm{~K} 1$ that runs along the embankment, the value is between 0.26 and 0.28 . Compared to other studies in tailings based on laboratory determinations (Ormann et al. 2011; Knutsson et al. 2018) these values are higher as shown in Table 3. Typically, Young's modulus in tailings is estimated in a triaxial compression test and depends on the surrounding pressure and the particle size distribution of the media. For instance, for a surrounding pressure of $200 \mathrm{kPa}, E$ value was 

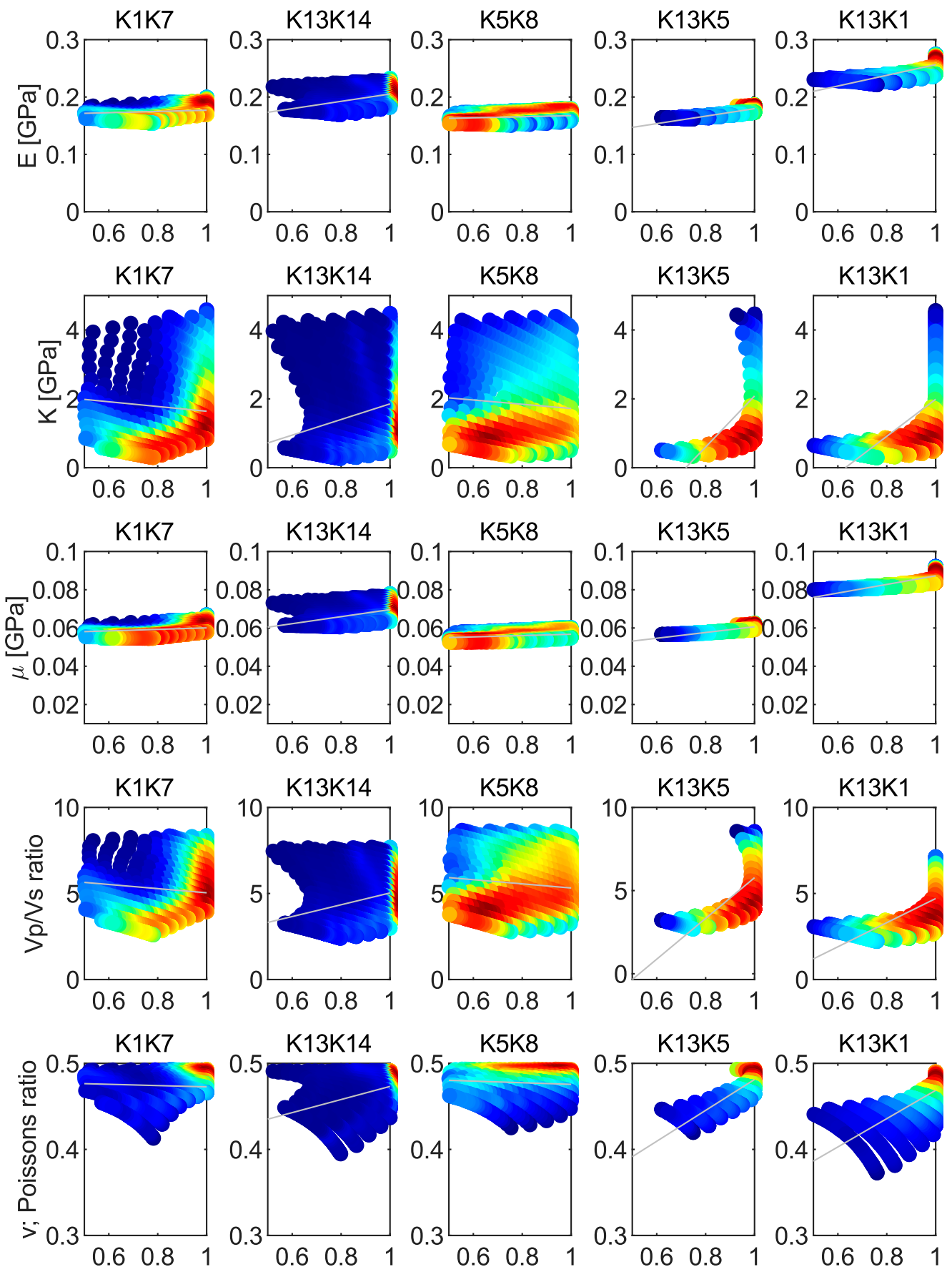

Water Saturation, $\mathrm{S}$

data density

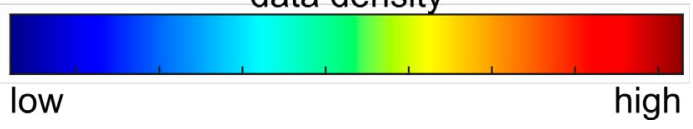

Figure 12. Elastic moduli versus calculated water saturation across the seismic refraction survey lines. Grey line across the density scatter plots is the least-square-fit line for over 9000 data points in each survey line. 
Table 3. Elastic parameters at predominant water saturation in the surveyed tailings area at Pyhäsalmi mine. Estimation based on seismic refraction and MASW analysis.

\begin{tabular}{|l|l|l|l|}
\hline Property & $\begin{array}{l}\text { Tailings } \\
(\mathbf{S}=\mathbf{0 . 8 - 1 . 0 )}\end{array}$ & $\begin{array}{l}\text { Embankment } \\
(\mathbf{S = 0 . 8 - 1 . 0 )}\end{array}$ & Other methods/studies \\
\hline Young's Modulus & $0.18(0.18-0.21)$ & $0.26(0.26-0.28)$ & $\begin{array}{l}0.01-0.02 \text { (Ormann et al. 2011; Knutsson et al. 2018; } \\
\text { Kerenchev 2019) }\end{array}$ \\
\hline Bulk modulus & $0.8(0.1-2.0)$ & $0.8(0.1-2.0)$ & - \\
\hline Shear modulus & $0.06(0.05-0.07)$ & $0.09(0.08-0.09)$ & $\begin{array}{l}0.01-0.04 \text { (James et al. 2011) } \\
0.02-0.08 \text { in-situ (Zhang and Lin 1982) }\end{array}$ \\
\hline$V_{p} / V_{s}$ ratio & $5.0(2.5-8.5)$ & $4.5(2.5-6.5)$ & $\begin{array}{l}2.8-5.6(\text { Tschuschke et al. 2020) } \\
2.2-4.5(J a m i o l k o w s k i \text { and Masella 2015) }\end{array}$ \\
\hline Poisson's ratio & $0.49(0.40-0.49)$ & $0.48(0.37-0.49)$ & $\begin{array}{l}\sim 0.40 \text { (Sotelo and Paihua 2017) } \\
0.3(\text { Psarropoulos and Tsompanakis 2008) }\end{array}$ \\
\hline porosity & 0.38 & 0.38 & - \\
\hline Void ratio & 0.62 & 0.62 & $0.6-1.0$ (Jamiolkowski and Masella 2015) \\
\hline
\end{tabular}

found to be about $0.03 \mathrm{GPa}$ for fine tailings and 0.034 for coarse tailings, whereas for a surrounding pressure of $600 \mathrm{kPa} E$ was found to be $0.05 \mathrm{GPa}$ for fine tailings, and 0.062 for coarse tailings (Lindquist $\&$ Tornqvist 2016). In other triaxial tests $\mathrm{E}$ in tailings range from 0.009 to $0.015 \mathrm{GPa}$ (Kerenchev 2019), or as low as $0.003 \mathrm{GPa}$ (Psarropoulos \& Tsompanakis 2008). Other reference combining seepage and stress estimated $E$ around $0.04 \mathrm{GPa}$ for silty sandy tailings and $v$ of 0.35 (Lu \& Chang 2019).

Regarding the Bulk modulus $(K)$ and under water saturation of $0.8-1.0$, the survey lines at different locations of the tailings have a wide range for $K$ between 0.1 to $2.0 \mathrm{GPa}$. The shear modulus is less dispersed but in the low range of $0.5-0.07$ GPa for tailings media and 0.08-0.09 GPa around the embankment. Shear modulus in tailings from cyclic laboratory testing at shear strains from 100 to $400 \mathrm{kPa}$ was found between 0.009 up to 0.04 GPa (James et al. 2011; Hu et al. 2017). Whereas in-situ downhole method with shear wave velocity measurements estimated the shear modulus to 0.02 GPa for shallow tailings and 0.08 GPa to a depth of $20 \mathrm{~m}$ (Zhang \& Lin 1982). The analysis also reveals the higher occurrence for the $V_{p} / V_{s}$ ratio around the values of 4.5-5. The upper limit for $V_{p} / V_{s}$ ratio is 8.5 for tailings media and 6.5 for the embankment at the condition of water saturation of $0.8-1.0$.
Poisson's ratio for all profile sections varies from 0.35 to 0.49 with higher occurrence in the upper limit at saturation. At the time of the survey, the values are in the range of $0.40-0.49$ for tailings in the impoundment and 0.37-0.49 for tailings near the embankment (possibly coarse and compacted).

\section{Discussion}

The seismic elastic velocities $\left(V_{p}\right.$ and $V$ ) and the elastic moduli are parameters that can provide important information about the physical and geotechnical condition of the tailings subsurface. The ratio of stress to strain deformation is measured by the elastic moduli parameters and depend on confining pressure, load magnitude, strength, stress, and drainage conditions (Duncan \& Bursey 2013).

For example, the $V_{p} / V_{s}$ ratio and Poisson's ratio are numeric values based on simple calculations and yet important indicators to evaluate the mass load of the tailings facility and its relationship with its physical stability. This is supported by studies in unconsolidated sediments comparable to tailings material, where the elastic velocities and Poisson's ratio increase as differential pressure increases. However, in over-pressurised conditions Poisson's ratio increases with a corresponding drop in elastic 

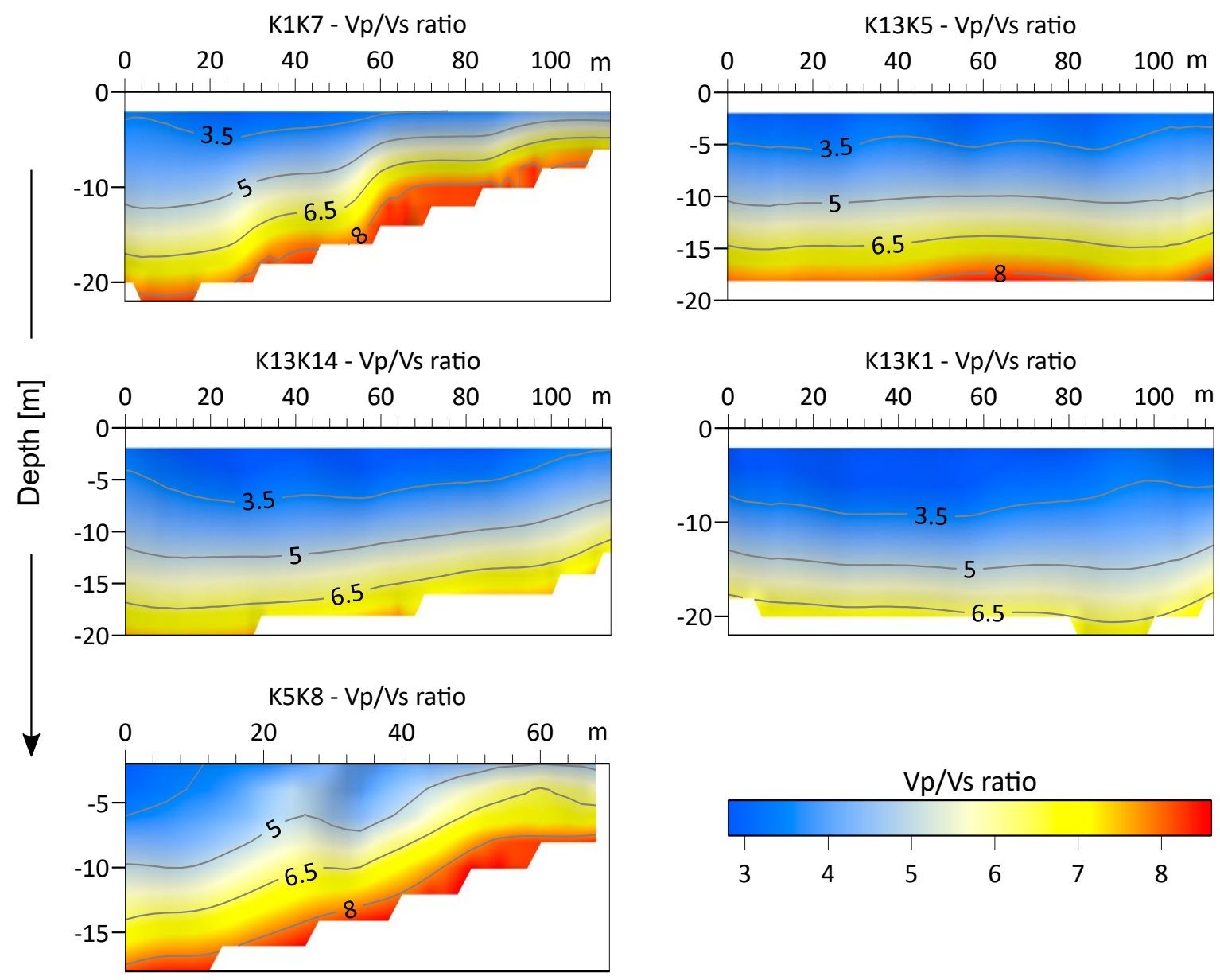

Figure 13. Vp/Vs ratio profiles along the survey lines in the tailings facility. From all the survey lines, only K13K1 is mapping the subsurface of the tailings near the embankment.

velocities, and very high $V_{p} / V_{s}$ ratio in the order of 10 or more (Lee 2003). The phenomenon is also observed in tailings facilities where the differential pressure increases as the mass load increases with ongoing tailings material being stored. This is illustrated in Fig. 13 for the tailings at Pyhäsalmi, where the maximum $V_{p} / V_{s}$ is shown at the bottom of the impoundment with a value around 8 . This also suggests that the tailings mass is not overpressurised, and that the tailings storage is at its full capacity. It is important also to note that the $V_{p} / V_{s}$ ratio is influenced by the level of the phreatic line and the elevated pore pressure under saturated conditions.
The effect of water saturation near and below the phreatic line on the main elastic parameters is presented in $2 \mathrm{D}$ cross-sections for line $\mathrm{K} 1 \mathrm{~K} 7$ in Fig. 14a. The analysis of the elastic moduli shows a quantitative and agreeable interpretation that water saturation causes weakness (strength reduction) in the tailings media and makes it softer (reduction of stiffness), both effects related to Young's modulus. Regarding the cross-section of Poisson's ratio, the bottom of the impoundment has high values. In Fig. 10, Poisson's ratio is higher in saturated tailings than in unsaturated tailings as $V_{p}$ and $V_{s}$ increase. This means that the tailings in saturated conditions can exhibit large elastic deformation even under 
the action of small amounts of strain or applied forces. A similar trend of increasing shear modulus is observed below the phreatic line in the tailings. Shear modulus depends on the $S$-wave velocity and bulk mass density and given that $S$-wave is not affected by water, the observed although marginal increase of $V$ is only dependent on the densification of tailings with depth. This agrees with the intuitive interpretation that tailings at the bottom are highly consolidated. Shear modulus as initial modulus is essential to the dynamic analysis of tailings dams (Zhang \& Lin 1982). The importance of using $\mathrm{S}$-waves for studying the saturated zone of the tailings is because Vs is independent of the water content in the pore space. Bulk modulus also increases with depth, and it is directly proportional to the confining pressure. Therefore, the bulk modulus in tailings is a function of the effective stress given by the total load and the excess pore pressure. High values of bulk modulus mean that volumetric deformation is not a serious problem under high confining pressures (Kwon et al. 2006).

For illustrating the applicability of determining elastic parameters in tailings, cross-sections for Young's modulus are presented in Fig. 14b. Young's modulus also known as the modulus of elasticity provide information about the stiffness of the tailings mass and is one of the factors used to calculate the material deformation under load. As expected, the stiffness that is related to Young's modulus increase with depth in the tailings and depends on the surrounding pressure. The interpretation concerning tailings is that smaller values of $E$ will increase the magnitude of displacement. The estimated values are higher in saturated tailings than in unsaturated tailings. The reasons may be that high $V_{p}$ and $V_{s}$ values at deeper zones in the tailings are influenced by the interlocking particles increasing stiffness (Guo \& Su 2007).

The methodology in this paper can be easily implemented in tailings facilities because these are engineered systems with known stratigraphy and geological boundaries. The tailings material falls within a narrow size classification of fine silty- sand particles, which are hydraulically deposited in the tailings facility and therefore the media is less heterogeneous. Knowledge about geological information is key to reduce the uncertainty in formulating the parameterisation of the initial conditions in the MASW analysis and model inversion to determine $S$-wave velocity. To the same extent, a reliable estimation of P-wave velocity by the SR method will increase confidence in the inversion model. Another important parameter is the bulk mass density of the layers considered as input in the inversion model. The variability of bulk mass density in tailings is not significant, although the nature of hydraulic deposition of tailings can lead to uneven distribution of tailings particles and stratification. With these considerations in mind, the only challenge is to obtain in-situ and noninvasive measurements of $\mathrm{P}$ - and $\mathrm{S}$-wave velocities which can be achieved by seismic refraction and MASW analysis. This paper has demonstrated that this is possible.

\section{Conclusion}

The tailings facility at Pyhäsalmi mine is a 20year decommissioned area that has undergone reclamation and as such, the site is inspected with relative frequency (i.e., yearly) to monitor the condition of the structure. In this paper, we used conventional seismic refraction data to retrieve both $\mathrm{P}$-wave and $\mathrm{S}$-wave velocity profiles of the tailings area. As the velocity of seismic waves is related to the elastic properties of the solid matrix, the insitu elasticity of the tailings media was interpreted via the elastic parameters and the associated hydrogeological conditions.

A joint interpretation of seismic refraction and tailings physics approach enabled the determination of elastic parameters (e.g., Bulk modulus, Young's modulus, Shear modulus, $V_{p} / V_{s}$ ratio, Poisson's ratio) and hydrogeological conditions (e.g., porosity, void ratio, water content, saturation). Bulk modulus refers to the volumetric deformation, Young's modulus to the tensile or compressive deformation, 


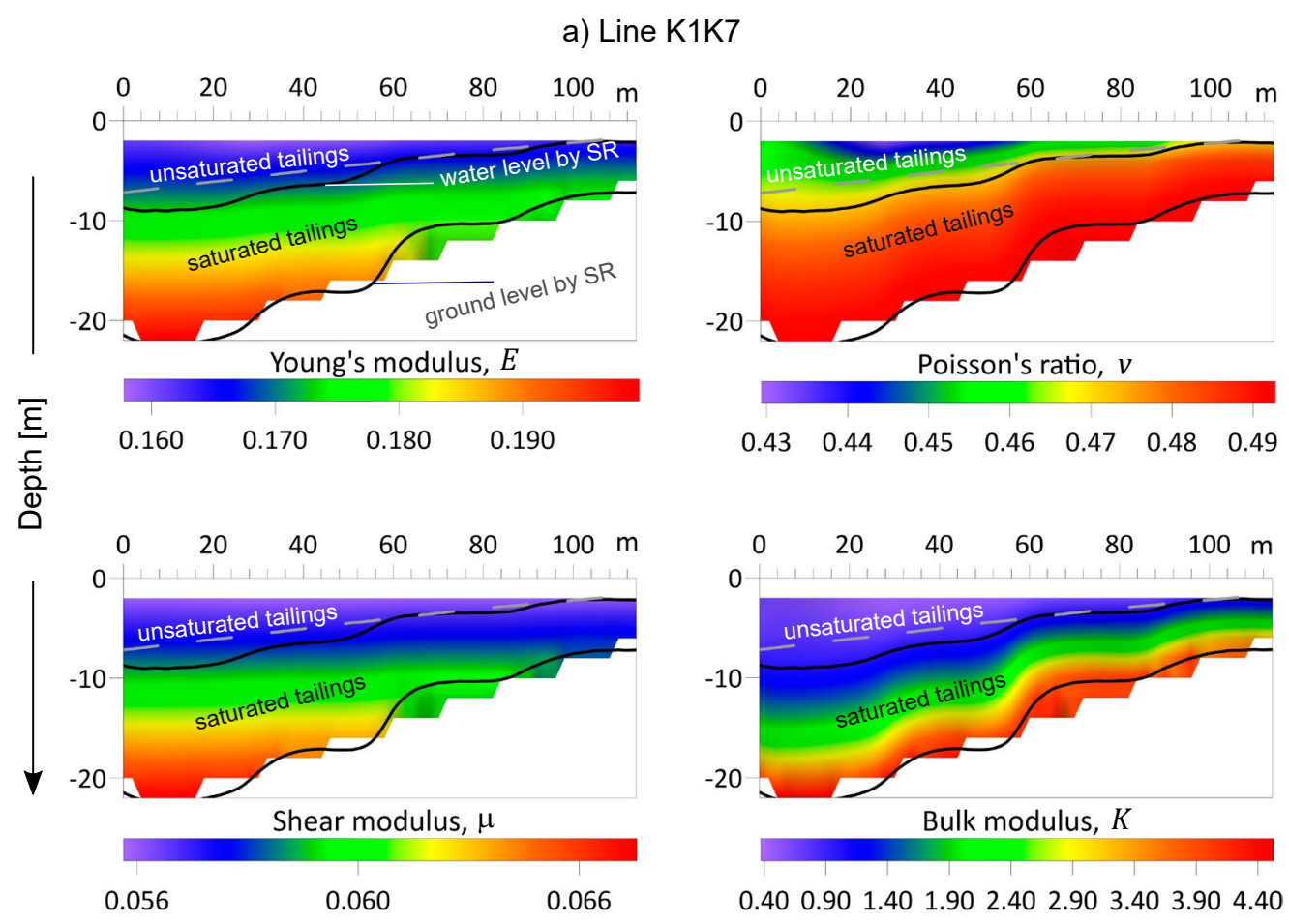

b) Young's modulus profiles

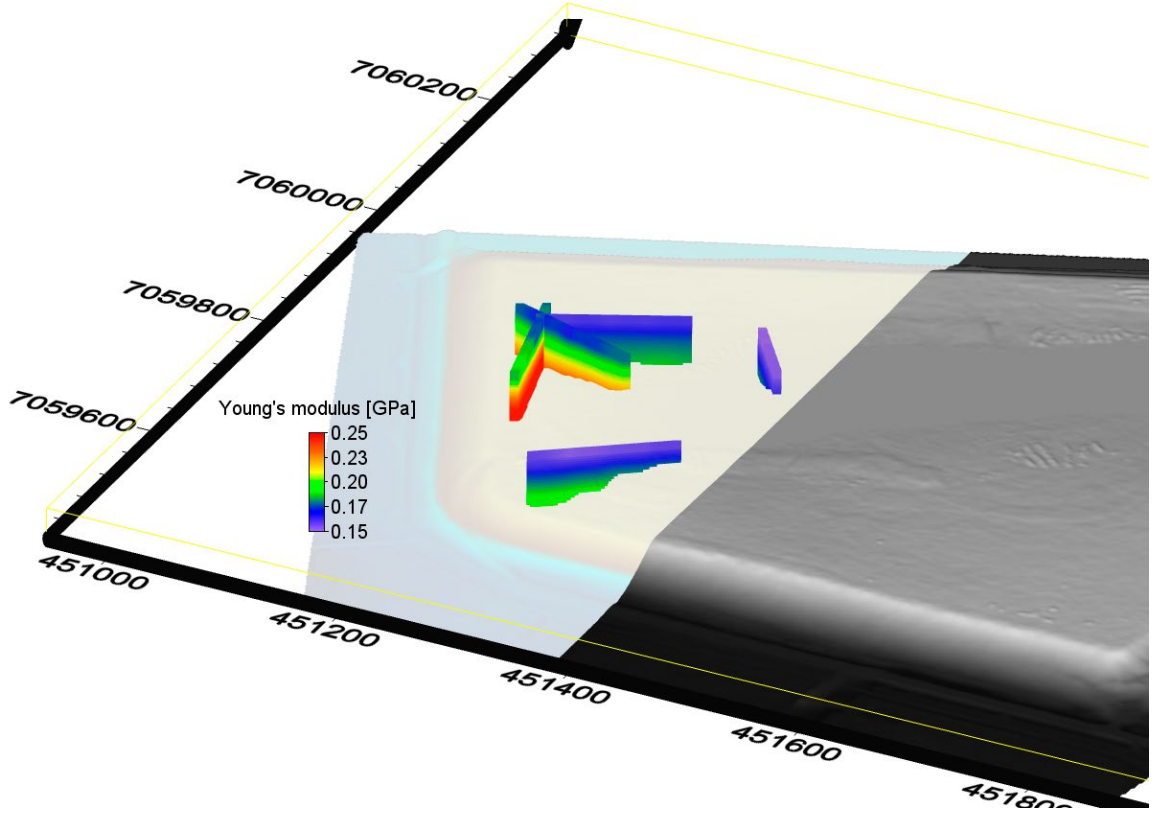

Figure 14. 2D cross-section examples of Elastic moduli determined by SR and MASW analysis. (a) principal elastic moduli sections for line K1K7. Black lines are SR inferred boundaries for water level (upper) and underlying ground level (lower). Grey dotted line is interpolated water level from piezometric measurements. (b) Young's modulus cross-section representation along all survey lines in the tailings facility of Pyhäsalmi mine. 
and shear modulus to the shear deformation. These values including the $V_{p} / V_{s}$ ratio provide with valuable information about how much force the tailings body mass can withstand before permanent deformation. For instance, the analysis of the data revealed a state of variable water saturation above the water table increasing from 0.4 and peaking around 0.8 saturation. For this condition, the bulk modulus $K$ that describes the resistance of the tailings by relating the change in hydrostatic stress to the volumetric strain varied predominantly between 1.0-2.0 GPa. The Young's modulus $E$ in the tailings media was in the low range of $0.15-0.23$ GPa regardless of the degree of saturation. Poisson's ratio values in all sections were in the upper limit, meaning that the tailings media is highly susceptible to transverse deformation under axial compression. Thus, the elastic seismic velocities and the elastic parameters in tailings media are influenced by the hydrogeological conditions and the physical heterogeneity in the tailings domain.

The paper demonstrates the applicability of seismic refraction and MASW analysis for mapping the subsurface of tailings in terms of geotechnical and hydrogeological conditions. It enables a noninvasive technology for in-situ monitoring and fast decision-making in the management of tailings facilities; however, the authors acknowledge the uncertainty to what extent the approach can source data for design and engineering purposes. Future work is recommended for determining the elastic parameters by using a dataset from tomographic seismic refraction and evaluating the results against conventional techniques such as SCPTU that is based on measurements of hydraulic pore water pressure and seismic velocities.

\section{Acknowledgments}

This project was supported by the European Union's Horizon 2020 research and innovation programme under the Marie Skoldowska-Curie grant agreement No 713606. The research work was funded by the K.H. Renlund foundation.
Acknowledgments to Pyhäsalmi mine for providing access to the site and Oulu Mining School where the research is conducted.

\section{References}

Anukwu, G. C., Khalil, A. E., Nawawi, M. \& Younis, A. M., 2020. Delineation of shallow structures in the vicinity of Ulu Slim hot spring using seismic refraction and MASW techniques. NRIAG Journal of Astronomy and Geophysics 9, 7-15. https://doi.org/10.1080/20909977.2019.1702803

ASTM, 2011. D5777-00 Standard Guide for Using the Seismic Refraction Method for Subsurface Investigation. ASTM Int.

Castagna, J. P., Batzle, M. L. \& Eastwood, R. L., 1985. Relationships between compressional and shear-wave velocities in clastic silicate rocks. 1984 SEG Annual Meeting SEG 1984 50, 582-584.

https://doi.org/10.1190/1.1894108

Cracknell, M. J., Nascimento, S. C., Heng, W. X., Schaap, T. A., Cracknell, M. J., Nascimento, S. C., Heng, W. X., Harbour, M., Cracknell, M. J. \& Parbhakar-fox, A., 2019. Geophysical investigation of mine waste in the King River Delta, Macquarie Harbour, Tasmania, in: AEGC2019 Data to Discovery - Perth, Australia. pp. 1-4. https://doi.org/10.1080/22020586.2019.12072938

Davis, E. H. \& Poulos, H.G., 1968. The use of elastic theory for settlement prediction under three-dimensional conditions. Geotechnique 18, 67-91. https://doi.org/10.1680/geot.1968.18.1.67

Duncan, J. M. \& Bursey, A., 2013. Soil Modulus Correlations, in: Proceedings of Geo-Congress 2013, San Diego, CA, USA. American Society of Civil Engineers, pp. 321-336. https://doi.org/10.1061/9780784412763.026

Geometrics Inc., 2005. SeisImager/2D Version 3.1; Pickwin v. 3.14; Plorefa v. 2.70.

Geopsy, 2021. Geopsy package [win64], Version 3.4.1.

Greenberg, M. L. \& Castagna, J. P., 1992. Shear-wave estimation in porous rocks: Theoretical formulation, preliminary verification and applications. Geophysical Prospecting https://doi.org/10.1111/j.1365-2478.1992.tb00371.x

Guo, P. \& Su, X., 2007. Shear strength, interparticle locking, and dilatancy of granular materials. Canadian Geotechnical Journal 44, 579-591. https://doi.org/10.1139/T07-010

Hu, L., Wu, H., Zhang, L., Zhang, P. \&Wen, Q., 2017. Geotechnical Properties of Mine Tailings. Journal of Materials in Civil Engineering 29, 04016220. https://doi.org/10.1061/(asce)mt.1943-5533.0001736

Idziak, A. F. \& Dubiel, R., 2011. Geophysics in Mining and Environmental Protection, GeoPlanet: Earth and Planetary Sciences. Springer. https://doi.org/10.1007/978-3-642-19097-1 
James, M., Aubertin, M., Wijewickreme, D. \& Wilson, G. W., 2011. A laboratory investigation of the dynamic properties of tailings. Canadian Geotechnical Journal 48, 1587-1600. https://doi.org/10.1139/t11-060

Jamiolkowski, M., \& Masella, A., 2015. Geotechnical Characterization of Copper Tailings at Zelazny Most Site. Proc. 3rd Int. Conf. Flat Dilatom. Keynote Lecture.

Kerenchev, N., 2019. On the e50 modulus of tailings dam materials, in: International Multidisciplinary Scientific GeoConference Surveying Geology and Mining Ecology Management, SGEM. pp. 399-404. https://doi.org/10.5593/sgem2019/1.2/S02.051

Knutsson, R., Viklander, P. \& Knutsson, S., 2018. Benefits of Advanced Constitutive Modeling when Estimating Deformations in a Tailings Dam. Journal of Earth Sciences and Geotechnical Engineering 8, 1-19.

Kwon, Y., Asano, T., Sento, N., Uzuoka, R. \& Kazama, M., 2006. Confining pressure-dependency of bulk modulus of sand during liquefaction. Structural Engineering / Earthquake Engineering 23, 149-158. https://doi.org/10.2208/jsceseee.23.149s

Landau, L.D. \& Lifshitz, E.M., 1970. Theory of Elasticity, 2nd Editio. ed, Course of Theoretical Physics. Volume 7. Pergamon Press Ltd. https://doi.org/10.1016/C2009-0-25521-8

Lee, M.W., 2003. Elastic properties of overpressured and unconsolidated sediments. U.S. Geological Survey Bulletin 2214, 1-10.

Lghoul, M., Teixidó, T., Peña, J. A., Hakkou, R., Kchikach, A., Guérin, R., Jaffal, M. \& Zouhri, L., 2012. Electrical and Seismic Tomography Used to Image the Structure of a Tailings Pond at the Abandoned Kettara Mine, Morocco. Mine Water and the Environment 31, 53-61. https://doi.org/10.1007/s10230-012-0172-x

Lindquist, A. \& Tornqvist, S., 2016. Stability analysis on a planned Mexican tailings dam. Master thesis. Uppsala University, Sweden.

Lu, X. H. \& Chang, X. S., 2019. Stability Analysis of Tailings Dam based on the Combination of Seepage and Stress. Journal of Physics: Conference Series 1168. https://doi.org/10.1088/1742-6596/1168/2/022067

Lu, Z., 2017. High-frequency MASW method and its applications, in: SEG International Exposition and 87th Annual Meeting. https://doi.org/10.1190/segam2017-17396701.1

Mavko, G., Mukerji, T. \& Dvorkin, J., 2020. The Rock Physics Handbook, 3rd Editio. ed. Cambridge University Press. https://doi.org/http://dx.doi. org/10.1017/9781108333016

Mollehuara Canales, R., Kozlovskaya, E., Lunkka, J. P., Guan, H., Banks, E. \& Moisio, K., 2020. Geoelectric interpretation of petrophysical and hydrogeological parameters in reclaimed mine tailings areas. Journal of Applied Geophysics 181, 104139.

https://doi.org/10.1016/j.jappgeo.2020.104139
Mollehuara Canales, R., Kozlovskaya, E., Lunkka, J. P., Moisio, K. \& Pedretti, D., 2021. Non-invasive geophysical imaging and facies analysis in mining tailings. Journal of Applied Geophysics 192, 104402.

https://doi.org/10.1016/j.jappgeo.2021.104402

Olafsdottir, E. A., Erlingsson, S. \& Bessason, B., 2018. Tool for analysis of multichannel analysis of surface waves (MASW) field data and evaluation of shear wave velocity profiles of soils. Canadian Geotechnical Journal 55, $217-$ 233. https://doi.org/10.1139/cgj-2016-0302

Olivier, G., Brenguier, F., de Wit, T. \& Lynch, R., 2017. Monitoring the stability of tailings dam walls with ambient seismic noise. The Leading Edge 36, 350a1-350a6. https://doi.org/10.1190/tle36040350a1.1

Ormann, L., Zardari, M. A., Mattsson, H., Bjelkevik, A. \& Knutsson, S., 2011. Numerical analysis of curved embankment of an upstream tailings dam. The Electronic journal of geotechnical engineering 16 I, 931-944.

Outokumpu Mining Oy, 1999. Pöyry 1999 report: Pyhäsalmen kaivos. Rikastushiekka-Allas rannan ja rannantien suuntaisten reunapenkereiden korotus, Vakavuuslaskelmat ja korotus.

Park, C.B., Miller, R.D. \& Xia, J., 1999a. Multichannel analysis of surface waves. Geophysics 64, 800-808. https://doi.org/10.1190/1.1444590

Park, C.B., Miller, R.D., Miura, H. \& Geological Survey, K., 1999b. Optimum Field Parameters of an MASW Survey, Kansas Geological Survey.

Pegah, E. \& Liu, H., 2016. Application of near-surface seismic refraction tomography and multichannel analysis of surface waves for geotechnical site characterizations: A case study. Engineering Geology 208, 100-113. https://doi.org/10.1016/j.enggeo.2016.04.021

Psarropoulos, P. N. \& Tsompanakis, Y., 2008. Stability of tailings dams under static and seismic loading. Canadian Geotechnical Journal 45, 663-675. https://doi.org/10.1139/T08-014

Pyhäsalmi Mine Oy, 2007. Ympäristölupavirasto. Lupapäätös 2007. Pyhäsalmen kaivoksen ympäristö- ja vesitalouslupa, Pyhäjärvi.

Redpath, B. B., 1973. Seismic refraction exploration for engineering site investigations, U. S. Army Engineer Waterways Experiment Station. https://doi.org/10.2172/4409605

Robertson, P. K. \& Cabal, K. L., 2014. Guide to Cone Penetration Testing, 6th Editio. ed. Gregg Drilling \& Testing, Inc, Signal Hill, California 90755.

Rucker, M., 2006. Integrating seismic refraction and surface wave data collection and interpretation for geotechnical site characterization, in: Conference on Applied Geophysics 2006. pp. 1-15.

Salem, H. S., 2000. Poisson's ratio and the porosity of surface soils and shallow sediments, determined from seismic compressional and shear wave velocities. Geotechnique 50, 461-463.

https://doi.org/10.1680/geot.2000.50.4.461 
Sambridge, M., 1999a. Geophysical inversion with a neighbourhood algorithm - I. Searching a parameter space. Geophysical Journal International 138, 479-494. https://doi.org/10.1046/j.1365-246X.1999.00876.x

Sambridge, M., 1999b. Geophysical inversion with a neighbourhood algorithm--II. Appraising the ensemble. Geophysical Journal International 138, 727-746. https://doi.org/10.1046/j.1365-246X.1999.00900.x

Sarkar, R., Kolathayar, S., Drukpa, D., Choki, K., Rai, S., Tshering, S.T. \& Yuden, K., 2021. Near-surface seismic refraction tomography and MASW for site characterization in Phuentsholing, Bhutan Himalaya. SN Applied Sciences 3, 1-18. https://doi.org/10.1007/s42452-021-04347-4

Schön, J. H., 2015. Physical Properties of Rocks: Fundamentals and Principles of Petrophysics, Second edi. ed. Elsevier B.V.

Sotelo, G. \& Paihua, S., 2017. Estimate of Settlement of a Tailings Dam Founded on Collapsible Soils: Case Study. Proceeding 4th International Seminar Tailings Management 1-15.

Soupios, P. \& Kokinou, E., 2016. Environmental geophysics: Techniques, advantages and limitations, in: Aiello, G. (Ed.), Geophysics: Principles, Applications and Emerging Technologies. Nova Publishers, New York, NY, pp. 1-45.

Sousa, G. M. \& Gomes, R. C., 2020. Obtaining geotechnical parameters from correlations between geophysics and CPT tests in tailings dams. REM - Internatinal Engineering Journal. 73, 453-462. https://doi.org/10.1590/0370-44672019730114
Tokimatsu, K. \& Uchida, A., 1990. Correlation between liquefaction resistance and shear wave velocity. Soils Found. 30, 33-42. https://doi.org/10.3208/sandf1972.30.2_33

Tschuschke, W., Gogolik, S., Wrózynska, M., Kroll, M. \& Stefanek, P., 2020. The application of the seismic cone penetration test (SCPTU) in tailings water conditions monitoring. Water (Switzerland) 12, 1-13. https://doi.org/10.3390/w12030737

Xia, J., Miller, R. D. \& Park, C. B., 2009. Estimation of nearsurface shear-wave velocity by inversion of Rayleigh waves. Geophysics 64, 691-700. https://doi.org/https://doi.org/10.1190/1.1444578

Yilmaz, Ö. \& Miller, R.D., 2015. Engineering Seismology: With Applications to Geotechnical Engineering, Investigations in Geophysics No. 17. Society of Exploration Geophysicists. https://doi.org/10.1190/1.9781560803300

Yusof, N. Q. A. M. \& Zabidi, H., 2018. Reliability of Using Standard Penetration Test (SPT) in Predicting Properties of Soil. Journal of Physics: Conference Series 1082. https://doi.org/10.1088/1742-6596/1082/1/012094

Zhang, B. \& Lin, Ch., 1982. Shear wave velocity and geotechnical properties of tailings deposits. Bulletin of the International Association of Engineering Geology 347-353. https://doi.org/10.1007/BF02594240 